\title{
3. Spectroscopic Methods of Characterization for Zeolites and MOFs
}

\author{
Luis F. Bobadilla, ${ }^{1}$ Laetitia Oliviero, ${ }^{2}$ \\ Francisca Romero-Sarria ${ }^{1}$ and Marco Daturi ${ }^{2}$ \\ ${ }^{1}$ Instituto de Ciencia de Materiales de Sevilla, Centro Mixto \\ CSIC-Universidad de Sevilla. Av. Américo Vespucio 49, 41092 \\ Sevilla, Spain. \\ ${ }^{2}$ Laboratoire Catalyse et Spectrochimie, ENSICAEN, Université \\ de Caen, CNRS, Bd. Maréchal Juin 6, F-14050 Caen, France.
}

\begin{abstract}
Keywords: Acidity, basicity, vibrational spectroscopy, IR spectrum, probe molecule
\end{abstract}

\section{Fundamentals}

Generally speaking, spectroscopic methods of analysis aim to determine the chemical composition of a sample through the interaction of an electromagnetic beam (EMB) with the matter. This beam is characterised by its intensity $\left(I_{o}\right)$ and its wavelength $\left(\lambda_{\circ}\right)$. The different beam-matter interaction modes involved in spectroscopic techniques are schematically described in Figure 1. The incident beam can be:

1) absorbed by the matter at the atomic, molecular or at a higher level, and the analysed beam is the transmitted one, which characterised by $\left(\mathrm{I}<\mathrm{I}_{o}, \lambda_{\circ}\right)$,

2) absorbed by the matter and lead to emission of electrons (photoelectric effect) or photons (fluorescence or phosphorescence phenomena with $\left.\lambda>\lambda_{\mathrm{o}}\right)$,

3) diffused by diffraction in ordered matter leading to constructive and destructive interferences, in this case the analysis focuses on the angle of diffraction,

4) diffused by reflection, the resulting beam having same $\lambda_{\circ}$ but lower intensity $\left(\mathrm{I}^{\prime}<\mathrm{I}_{\mathrm{o}}\right)$. 


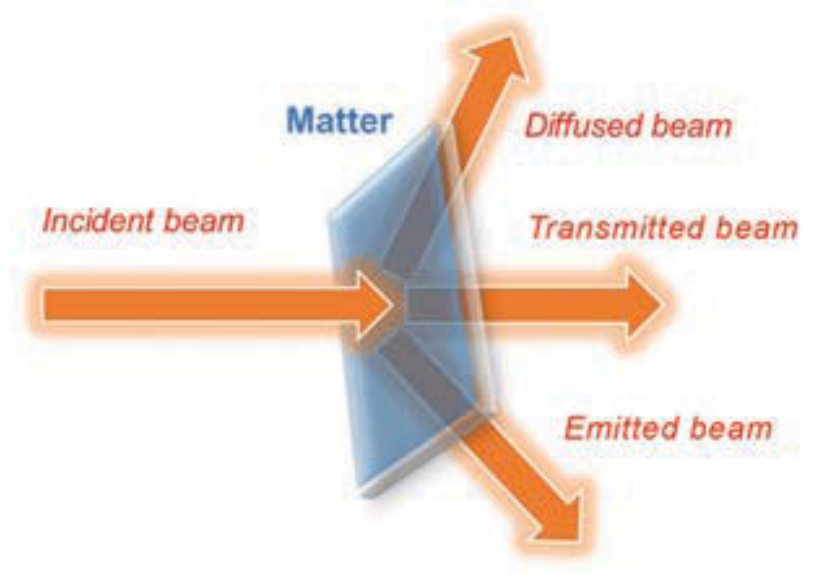

Figure 1. Interaction EMB-matter.

Table 1. Energy range and obtained information of the main spectroscopic methods.

\begin{tabular}{|c|c|c|}
\hline $\begin{array}{l}\text { EMB (energy } \\
\text { range, eV) }\end{array}$ & $\begin{array}{l}\text { Spectroscopy name } \\
\text { (phenomena) }\end{array}$ & Information \\
\hline $\begin{array}{l}\text { Y-ray } \\
\left(1.210^{9}-1.210^{6}\right)\end{array}$ & Mössbauer (absorption/emission) & Nuclear atomic transition \\
\hline \multirow[t]{2}{*}{$X-\operatorname{ray}\left(10^{5}-10^{2}\right)$} & $\begin{array}{l}\text { EXAFS/XANES (absorption) } \\
\text { EDX (emission) } \\
\text { XPS (electron emission) }\end{array}$ & $\begin{array}{l}\text { Internal electrons } \\
\text { Atomic composition } \\
\text { Atomic composition, oxidation } \\
\text { number }\end{array}$ \\
\hline & $\mathrm{XRD}$ (diffraction) & Atomic arrangement, structure \\
\hline UV-visible (1-10) & UV-visible (absorption) & $\begin{array}{l}\text { External electrons, molecular } \\
\text { bonds, oxidation degree }\end{array}$ \\
\hline $\operatorname{IR}(0.1-1)$ & IR (absorption) Raman (diffusion) & Molecule vibration/rotation \\
\hline
\end{tabular}

EXAFS: extended X-ray absorption fine structure, XANES: X-ray absorption near edge structure, EDX: energy-dispersive X-ray spectroscopy, XPS: X-ray photoelectron spectroscopy.

According to the energy associated with the incident or emitted beam, a range of information can be obtained, as summarised in Table 1, giving rise to the usual spectroscopic techniques.

The objective of the characterization of materials in heterogeneous catalysis is to understand the activity and selectivity of solid catalysts in a given reaction. Heterogeneous catalysis relies on the solid-gas or solid-liquid interface but also on the accessibility of active sites. Because of the wide 
range of energies associated with spectroscopic methods, complementary information about the material as well as the reaction mechanism can be obtained by a proper combination of techniques. Bulk characterization information must be distinguished from surface information, even if they are related. Also, an important distinction has to be made between techniques that characterise the material as prepared and the ones that allow the characterization of the catalyst during its operation, an intermediate one being in situ characterization. Note that, in addition to the study of the activity/selectivity of the catalytic reaction, these operando and in situ approaches, also allow for studying formation (crystallization) of the material during its synthesis, particularly in the case of zeolitic and hybrid materials.

In the case of zeolite and MOF characterization, the determination of the atomic arrangement composing the $3 \mathrm{D}$ structure is mainly performed by X-ray diffraction and NMR spectroscopy. EXAFS and XANES spectroscopies could complete the description about the order/disorder at a more local level. Such information is relevant in order to verify the synthesis and purity of the material but also to understand the transport phenomena of reactants and products inside the porous material. In the case of zeolites, the main structures are described in the Database of the International Zeolite Association [1].

$\mathrm{X}$-ray photoelectron spectroscopy is used to discern the global chemical composition of the external layer of a solid $(<2-3 \mathrm{~nm})$ and, more specifically, the distribution of the oxidation number for each element. Note that this technique requires low pressure and is mainly used as an ex-situ technique. Also, in the case of highly porous materials like zeolites and MOFs, a great deal of the area inside the (micro)pores may not be analysed, even though it can contribute to activity. For specific atoms such as iron or cobalt, Mössbauer spectroscopy allows following the oxidation state and coordination number in in situ conditions. Energy-dispersive $\mathrm{X}$-ray spectroscopy, EDX, is performed in an electron microscope and also allows determination of the chemical composition but in a more localised region (usually in a volume of around $1 \mu \mathrm{m}^{3}$ ). UV-visible spectroscopy allows identifying the elements and their oxidation number as well as their local arrangements. The use of this technique in in situ conditions can also give information on the adsorbed species and on the modification of the coordination of transition metal ions in zeolites. However, the resolution of this technique is low since the coexistence of different species makes their distinction difficult. 
Vibrational spectroscopies (IR, Raman) can be used first to get information on the structure of zeolites and MOF. Vibrational spectroscopies are especially useful to establish structure-activity relationships since they also allow distinguishing various surface species according to their local environment. The ideal characterization of the catalyst is indeed the one able to reach the concentration of individual, independent sites in order to determine their intrinsic activity. Vibrational spectroscopies are also informative for studying the reaction mechanism: they can allow the identification of intermediates, poisons or spectators species, even if the distinction between these various species is not always straightforward. The main limitation in this regard is that reactive intermediates have a short lifetime on the catalyst surface. As a result, new fast spectroscopic devices are under development. Since vibrational spectroscopies have a specifically wide application domain in the field of zeolite and MOFs, their common fundamental basis will be shortly described next.

Vibrational spectroscopy involves transitions between discrete vibrational energy levels of polyatomic species, which are associated with their different vibration modes. Such modes can be described, as a first approximation, considering a chemical bond in a molecule or solid lattice as a harmonic oscillator (like two masses $\mathrm{m}_{1}$ and $\mathrm{m}_{2}$ bound by an ideal spring). The corresponding allowed transitions between equidistant vibrational energy levels are the ones with a one-unit increase in the vibrational quantum number (v), the so-called fundamental vibrations. A more realistic model is provided by the anharmonic oscillator, which is particularly relevant for explaining overtones (vibrational transitions with $\Delta v>1$ ). For the description of this model, the reader is referred to reference [2]. The frequency of the vibration according to the harmonic oscillator model is given by the following relation:

$$
\nu=\frac{1}{2 \pi} \sqrt{{ }^{k} / \mu}
$$

where $\mathrm{k}$ is the bond force constant and $\mu$ is the reduced mass, $\mu=\mathrm{m}_{1} \cdot \mathrm{m}_{2} /$ $\left(m_{1}+m_{2}\right)$. In this model, the higher the frequency (or the wavenumber), the stronger the bond.

For a given molecule of $\mathrm{N}$ atoms, there are $3 \mathrm{~N}-6$ fundamental vibrations $\left({ }_{3} \mathrm{~N}-5\right.$ in the case of a linear molecule). The nomenclature of these fundamental vibrations is shown in Figure 2. The stretching $(v)$ vibrations lead to a change in bond length and can be either symmetric or asymmetric. Bending vibrations $(\delta)$ correspond to a variation of angles in the plane of the atoms involved and include the rocking vibration of the tetrahedral unit. Variation of angles out of the plane of the atoms is named either bending 


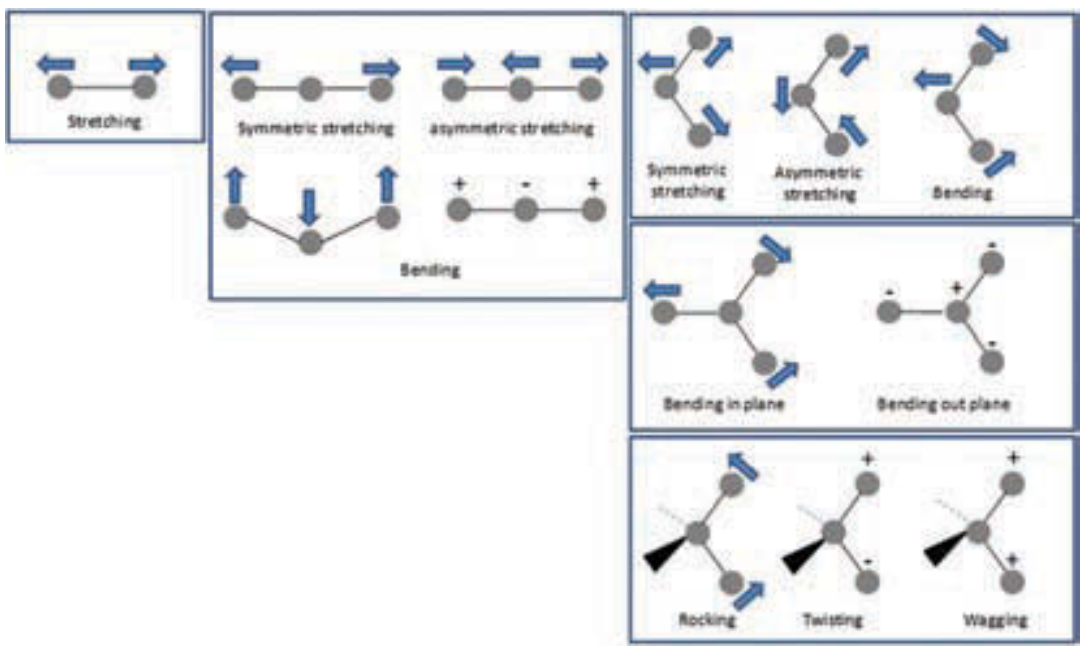

Figure 2. Representation of fundamental vibration modes.

out of plane or $\gamma$ vibration and includes the wagging mode of the tetrahedral unit. Finally, torsion $(\tau)$ vibration, such as the twisting of a tetrahedral unit, changes the angle between two atomic planes.

In IR spectroscopy, absorption of the incident beam occurs if its frequency corresponds to the frequency of the vibration and if during the vibration the dipole moment of the molecule is changed. In Raman spectroscopy, the vibration frequency appears as a Raman shift of the incident frequency due to scattering and implies that the polarisability of the molecule is changed during the vibration.

\section{General characterization}

To characterise the structure of zeolitic materials, the main vibrations of the primary building units $\left(\mathrm{TO}_{4}\right.$ tetrahedra) are reported in Table 2 according to references [3] and [4]. Raman spectra can be measured directly, whereas for IR spectra a dilution of the sample in a transparent media (such as $\mathrm{KBr}$ ) is often necessary, due to the strong absorptivity of the materials.

The position of the cations counterbalancing the lattice charge can also be characterised by vibrational spectroscopy. These vibrations occur in the $5^{0}-250 \mathrm{~cm}^{-1}$ domain. It has been shown that the frequency vibration depends on the charge and mass of the counter ion and also on the position inside the porous structure [5]. 
Table 2. Main vibration domains of internal and external linkages in zeolites.

\begin{tabular}{lllc}
\hline Internal tetrahedra & Vibrations $\left(\mathbf{c m}^{-1}\right)$ & External linkages & Vibrations $\left(\mathbf{c m}^{-1}\right)$ \\
\hline Asym. stretch & $1250-920$ & Double ring & $650-500$ \\
Sym.stretch & $720-650$ & Pore opening & $420-300$ \\
T-O bend & $500-420$ & Asym. stretch & $1150-1050$ \\
& & Sym. stretch & $870-750$ \\
\hline
\end{tabular}

In the case of organic-inorganic materials, the skeletal vibrations can be found below $1000 \mathrm{~cm}^{-1}$ for the transition metal-oxygen bonds, and between 1700 and $1200 \mathrm{~cm}^{-1}$ for the organic $\mathrm{C}-\mathrm{O}, \mathrm{N}-\mathrm{O}$ or $\delta(\mathrm{CH})$ vibrational modes.

On the other hand, the stretching vibration of the surface hydroxyl groups gives rise to several bands characterizing their position in the zeolite structure [6]. In the case of zeolite $Y$ for instance, the band at $3745 \mathrm{~cm}^{-1}$ is attributed to silanol groups (terminal or extra lattice), the one at $3655 \mathrm{~cm}^{-}$ ${ }^{1}$ to $\mathrm{OH}$ of extraframework aluminium, the ones at 3630 and $3560 \mathrm{~cm}^{-1}$ to bridging SiOHAl groups in the supercage and in smaller cavities, respectively $[7,8]$. MOFs also present $\mathrm{OH}$ vibrations in the $375^{\circ-3600 ~ \mathrm{~cm}^{-1}}$ range, when the cations are coordinatively unsaturated $[9,10]$.

Zeolite materials can present different sites, such as Brønsted or Lewis acid sites, basic sites and redox sites. To understand the catalysis on the material, these have to be distinguished and quantified in concentration and strength, taking into account their accessibility. To this end, adsorption of probe molecules followed by IR spectroscopy is an informative method. Indeed, the selection of molecules with variable basic strength allows for probing the acid strength of the solid. In the same manner, varying the size of the probe molecule allows for characterization of the accessibility of such sites. Ideally, the expected reactant can also be used as a probe in order to get information on its adsorption mode, which is related to its activation on the surface. In the following section, a description of the main probes used to characterise Brønsted and Lewis acidity and redox properties of a zeolite is presented.

\subsection{Acidity analysis}

Acidity is classically described by the Brønsted and Lewis concepts. Brønsted sites are proton donors, which can be directly detected by their $\mathrm{O}-\mathrm{H}$ vibrations, notably in the $3800-3500 \mathrm{~cm}^{-1}$ stretching interval. From a 
general point of view, the position of the vibration provides an approximate indication of its strength: acidity increases when $v(\mathrm{OH})$ decreases. This is true for a set of bands on the same sample, but cannot be used as a rule to compare different materials due to the structural and topological parameters influencing such vibrations. For example, linear hydroxyls are generally weakly acidic, whereas bridged hydroxyls are more acidic, due to the fact that the oxygen bond to the surface is stronger, so that the $\mathrm{O}-\mathrm{H}$ bond must be weaker. However, the amount of information that can be gathered from the bare hydroxyl IR spectrum is limited and the use of probe molecules is necessary, notably to separate the bands in a heterogeneous massif, to compare the acid strength or to verify the accessibility of the sites. In this case, three complexes can be formed between the basic probe (B) and the hydroxyl proton: i) a weak H-bond (B-...H-O), ii) a strong H-bond, giving rise to a quasi-symmetrical complex $(\mathrm{B} \cdots \cdot \mathrm{H} \cdot \cdots \mathrm{O})$, and iii) protonation, i.e. the formation of an ion pair with more or less dissociate ions $\left(\mathrm{BH}^{+} \ldots \mathrm{O}^{-}\right)$.

In the case of Lewis acid sites, the absence of a direct IR signal makes the use of probe molecules compulsory to characterise the acidity. This is obtained by analysing the molecular interactions between the surface and the basic probe, considering the band frequency and intensity in the spectrum of the perturbed probe with respect to the spectrum of the isolated molecule [11,12]. Upon different calibrations, this indicates the kind of sites and their surface concentration. Therefore an appropriate probe has to be chosen in order to obtain qualitative and quantitative information. The ideal probe molecule should have an optimum basic strength (sufficient to bond with the acid site, not too high to perturb it), an adequate size to access the porosity of the sample, a good selectivity towards the different sites, a satisfactory spectral response (in terms of intensity and shift proportional to the interaction strength), a good stability on the catalyst (no decomposition) and a sufficient vapour pressure to be introduced into the experimental cell.

\section{$\mathrm{H}_{2} \mathrm{O}$}

An efficient way to test Lewis sites is to transform them into Brønsted sites by a reversible adsorption of water. Each water molecule coordinated onto an activated sample induces the creation of two Brønsted sites presenting bands in the region $3700-3580 \mathrm{~cm}^{-1}[9,10]$. It is worth remarking that over oxidic compounds presenting Lewis acid-base pair water molecules are dissociated and form two hydroxyls as well. Other protic molecules (such as alcohols) can coordinate on Lewis sites and transform them into Brønsted acid sites whose acid strength is proportional to the acidity of the adsorptive $[10]$. 
CO

Based on the aforementioned concepts, $\mathrm{CO}$ is often considered as the ideal probe, being small in size, having very weak interactions, and with a spectral shift of more than $90 \mathrm{~cm}^{-1}$ depending on the strength of the acid site [13]. Being a very weak and soft base is very suitable for the characterization of strongly acidic surfaces. The wavenumber of the linear $v(\mathrm{CO})$ stretching vibration of molecules adsorbed at acidic centres without electron back donation is shifted to higher wavenumbers than gaseous CO $\left(2143 \mathrm{~cm}^{-1}\right)$, giving rise to bands between 2150 and $2180 \mathrm{~cm}^{-1}$ when interacting with Brønsted acid sites, or up to $2240 \mathrm{~cm}^{-1}$ for Lewis sites $[14,15]$. This shift can be explained in simple terms by the Blyholder model [16], due to the interaction of the filled $5 \sigma$-orbital of $\mathrm{CO}$ (HOMO) with an electron acceptor centre at the surface. This orbital is slightly antibonding between $\mathrm{C}$ and $\mathrm{O}$. Withdrawing of electrons from this orbital strengthens the $\mathrm{CO}$ bond. Electron $\pi$-backdonation from d-orbitals of surface transition metals atoms to the $2 \pi *$ - orbital of CO (LUMO) would partially weaken the CO bond. But globally the $\mathrm{CO}$ bond is strengthened, which results in a blueshift (higher wavenumber) of the corresponding $\nu(\mathrm{CO})$ vibration [17]. The higher the blueshift, the higher the Lewis acidity. To a certain extent, Brønsted acid sites can also be characterised with $\mathrm{CO}$ due to weak hydrogen bonding to surface $\mathrm{OH}$ groups. Accordingly, adsorption being weak, it should be favoured by low temperatures ranging down to the boiling point of nitrogen $(77 \mathrm{~K})$. In this case, $\mathrm{CO}$ and $\mathrm{OH}$ wavenumbers are shifted due to mutual interaction [18]. A linear correlation can be observed between the $\nu(\mathrm{OH})$ shift, the $\mathrm{H}_{\mathrm{o}}$ (Hammet acidity function) value and the $v(\mathrm{CO})$ band position, which allows ranking of the solid acidity among a large panel of compounds [10].

\section{(Substituted) pyridine}

Pyridine is certainly the most employed molecule to probe acidity. It has a strong base $\left(\mathrm{PA}=93 \mathrm{O} \mathrm{kJ} \mathrm{mol}^{-1}, \mathrm{pK}_{\mathrm{B}}=8.75\right)$ and it easily gives rise to the formation of H-bonded and pyridinium ion species on weak and strong Brønsted acid sites, respectively, and to coordinated species on Lewis acid sites [19]. Spectral analyses are generally performed over the $1400-1700 \mathrm{~cm}^{-1}$ $v(\mathrm{C}=\mathrm{C})$ ring vibrations range, in which four fundamental modes occur, accounting for the nature of the species formed. Among them, pyridinium species (Brønsted acid sites) are characterised by bands at 1640 and $1545 \mathrm{~cm}^{-1}$, whereas coordinated pyridine species give rise to bands at about

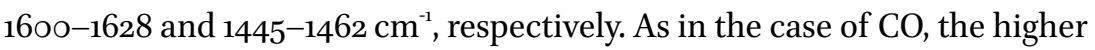
these frequencies are, the stronger the Lewis acidity is. Concerning H-bonded species, the corresponding bands are less sensitive and show vibrations at 

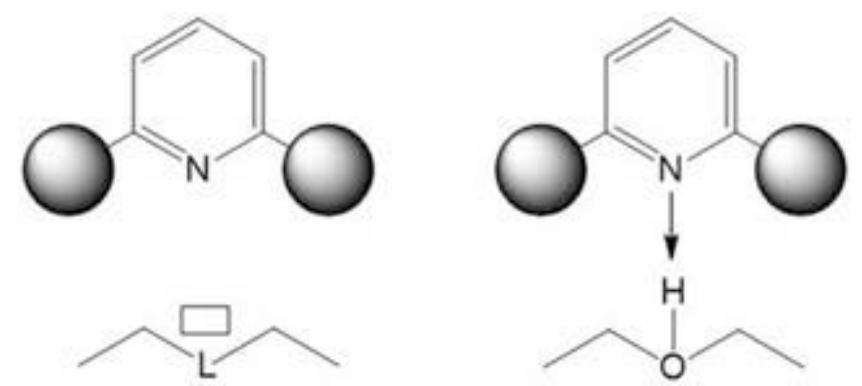

Figure 3. Interaction of substituted pyridine with the surface sites.

wavenumbers closer to the ones observed in the liquid phase (1596 and $1445 \mathrm{~cm}^{-1}$ ). Such small shifts can make assignments ambiguous when both weak Lewis and Brønsted acid sites are expected on the surface. Therefore, the only way to prove the formation of H-bonded species is the concomitant observation of a broad $v(\mathrm{OH})$ band shifted to a lower wavenumber than that corresponding to the free $\mathrm{OH}$ groups. Moreover, these species, hold relatively weakly on the surface hydroxyl groups, are easily removed by pumping off at $423 \mathrm{~K}$.

Pyridine is frequently used in quantitative studies by introducing successive aliquots of the probe on an activated surface. The progressive growing of the band intensity allows quantifying the concentration of the accessible acid sites on the solid. Then, operating a thermal desorption after surface saturation permits distinguishing the sites by acid strength. However, DMP (dimethylpyridine or lutidine) is more convenient than pyridine to detect weak Brønsted acidity due to its higher basicity $\left(\mathrm{pK}_{\mathrm{a}}=6.7\right.$ compared with 5.2 for pyridine) and also due to the interaction of the methyl groups with the surface favouring DMP adsorption on Brønsted acid sites, as schematised in Figure 3 [20]. Various adsorption modes of DMP with the surface of a solid give rise to specific spectral features in the $166 \mathrm{o}-158 \mathrm{o} \mathrm{cm}^{-1}$ range [21-24]. In particular, weakly adsorbed species (H-bonded or $\pi$-coordinated) produce absorption bands at $\sim 1600-1580 \mathrm{~cm}^{-1}, \sigma$-coordinated species on coordinatively unsaturated cations lead to bands around 1615-16oo and $158 \mathrm{o} \mathrm{cm}^{-1}$, the protonated species $\mathrm{DMPH}^{+}$absorbs near $165^{\mathrm{O}-1645}$ and $1625 \mathrm{~cm}^{-1}$.

\section{Ammonia}

Ammonia can be very useful as an acidity probe, although in some cases it is too reactive and gives rise to dissociative adsorption [25], disproportionation reaction, or is transformed into amide, imide and hydrazine 
species, as well as oxidised to $\mathrm{N}_{2}, \mathrm{~N}_{2}^{-}$and $\mathrm{N}_{3}^{-}[26]$. It is a good probe for acidic non-oxidizing or poorly oxidizing surfaces [27].

\section{Acetonitrile}

Acetonitrile is a probe with medium basicity that can interact with Lewis and Brønsted sites to form, depending on the acid strength of the site, protonated species or species strongly bound to the electrophilic site via a hydrogen bond in the case of $\mathrm{OH}$ groups. The $\mathrm{pK}_{\mathrm{a}}$ of $\mathrm{CH}_{3} \mathrm{CNH}^{+}$is 11.8, and protonation of acetonitrile only takes place with acids approaching the limit of superacidity. $\mathrm{CD}_{3} \mathrm{CN}$ is generally used in place of $\mathrm{CH}_{3} \mathrm{CN}$ because the latter molecule displays not only one but two bands in the $v(\mathrm{C} \equiv \mathrm{N})$ region used to characterise the acidity. This is due to a Fermi resonance between the fundamental $v(\mathrm{C} \equiv \mathrm{N})$ vibration and the combination mode $\delta_{\mathrm{S}}\left(\mathrm{CH}_{3}\right)+$ $v(\mathrm{C}-\mathrm{C})$. This interaction does not exist in the case of $\mathrm{CD}_{3} \mathrm{CN}$, which presents in the liquid state only one $v(\mathrm{C} \equiv \mathrm{N})$ band at $2263 \mathrm{~cm}^{-1}$, which shifts to a higher wavenumber upon interaction with acid sites [28].

Different nitriles can be used as acidity probe molecules, such as pivalonitrile, benzonitrile or $o$-toluonitrile [29,30]. The reference bands corresponding to the $v(\mathrm{C} \equiv \mathrm{N})$ vibration are close to that of acetonitrile, and they also undergo a blueshift proportional to the site acidity. The main difference consists in the steric hindrance of the molecule, which can be selectively used to probe sites inside the channels of porous materials, as described below.

\subsection{Site accessibility}

The description of the position of the sites inside the porosity of a zeolite or a MOF is of paramount importance, notably to correlate the site properties with their reactivity. For this purpose, different strategies have been elaborated to analyse the type, the concentration of sites and their strength inside the channels and the pockets of zeolitic compounds. The majority of the molecules mentioned above (CO, ammonia, acetonitrile, etc.) are small enough to enter the totality of the cavities. On the contrary, molecules with a greater steric hindrance (larger nitriles, substituted pyridine, etc.) can only enter large cavities. This has been largely applied to FAU and MOR structures, made of big and small cavities, in which some acidic hydroxyls are out of reach of basic molecules such as pyridine. Therefore, by operating co-adsorption of molecules presenting different sizes and basicity it is possible to determine the populations of the sites and their location inside 
the porosity. For example, the co-adsorption of the strongly basic trimethylamine and $\mathrm{NH}_{3}$ has provided, for the first time, an infrared evidence of four distinct acidic hydroxyls in defect-free HY. These sites have different acidic strengths and provide therefore various coordination environments to the ammonia and ammonium species inside the sample [31,32].

Pivalonitrile is too large a molecule to enter the side pockets of Mordenites, so the adsorption sites present there can be distinguished from those inside the main cavities by using various nitriles [29]. $O$-toluonitrile is larger than the channels of MOR, MIF and FER zeolites, thus allowing selective probing of their external surface and determination of the role of sites outside the porosity [30,33].

Accessibility can also be derived from infrared spectroscopy of substituted alkylpyridines with different sizes (pyridine: $0.57 \mathrm{~nm}, 2,6$-lutidine: $0.67 \mathrm{~nm}$, collidine: $0.74 \mathrm{~nm}$ ). For example, the enhanced accessibility of hierarchical ZSM- 5 crystals containing different degrees of intracrystalline mesoporosity was demonstrated this way. A relatively bulky molecule such as collidine, which probes practically no acid sites of the parent medium pore MFI structure, could access up to $40 \%$ of the Brønsted sites in the hierarchical sample [34].

\subsection{Basicity}

Basicity is a property more difficult to test than acidity, due to the intrinsic characteristics of the basic site [35]. $\mathrm{CO}_{2}$ is often used as probe molecules for the characterization of basic oxides: the subsequent formation of carbonates provides reliable indications on the kind and strength of basic sites on the material surface, considering both the symmetry of the formed species and their thermal stability [36]. However, carbonates strongly modify the probed solid and in the case of zeolitic compounds the framework oxygen basicity is generally too low to induce their formation. Thus, molecule alternatives to $\mathrm{CO}_{2}$ (or $\mathrm{NO}_{2}$ and $\mathrm{SO}_{2}$, which acting in the same way will form nitrates and sulphates, demonstrating the presence of basic sites) have to be used. Some years ago, Lavalley reviewed the infrared spectroscopic studies of the surface basicity of metal oxides and zeolites using adsorbed probe molecules [37]. Results obtained from carbon monoxide, carbon dioxide, sulphur dioxide, pyrrole, chloroform, acetonitrile, alkanes, thiols, boric acid, trimethyl ether, ammonia, and pyridine were discussed and their drawbacks were highlighted. Even if it was clearly stated that no probe could be used universally, pyrrole appeared to be quite suitable in 
the case of alkaline zeolites. A pioneering review on the basic properties of zeolites was conducted by Barthomeuf [38].

More recently, $\mathrm{NO}_{2}$ disproportionation on alkaline zeolites was used to generate nitrosonium $\left(\mathrm{NO}^{+}\right)$and nitrate ions whose infrared vibrations are shown to be very sensitive to the chemical hardness of the cation and the basicity of zeolitic oxygen atoms [39]. In general, the best probe molecule for IR measurements would be an H-donating $\mathrm{HX}$ molecule able to adsorb on surface centres such as $-\mathrm{O}^{2-}$ or $-\mathrm{OH}^{-}$sites through a hydrogen bond interaction. From the $v(\mathrm{H}-\mathrm{X})$ shift, a scale of surface basicity could be established [40]. Knözinger proposed a way to obtain a relative ranking of the basic strength of a series of catalyst materials by FT-IR spectroscopy using methylacetylene and tert-butylacetylene as probe molecules [41].

Michalska et al. pointed out that propyne is an excellent probe for the study of oxygen basicity in mesoporous molecular sieves [42]. Additionally, they verified that probe dissociation does not depend on the site strength but can be due to the presence of Lewis-acid sites coupled with basic sites: the formation of the hydrogen bond weakens the bond between $\equiv \mathrm{C}$ and $\mathrm{H}$. In the presence of an acid site, which can host the $\mathrm{CH}_{3}-\mathrm{C} \equiv \mathrm{C}$ moiety, the surface protonation is easily achieved. Therefore, propyne dissociation is a good probe for the presence of acid-base pairs on a surface as well [42]. In a similar way, propyne highlighted the presence of acid-base pairs in MIL$53(\mathrm{Fe})-\mathrm{CH}_{3}$. The bridging hydroxyl group $\mu_{2}-\mathrm{OH}$ acts as a proton donor toward the $\mathrm{C} \equiv \mathrm{C}$ triple bond of propyne and as proton acceptor toward the $\equiv \mathrm{C}-\mathrm{H}$ group, thanks to the simultaneous presence of an acid and a basic function in the propyne molecule, which is not the case for other probe molecules [43]. This approach also allowed the correlation of basic properties in solid catalysts (such as lanthanum oxides) with their performances for the synthesis of phytosterol esters from transesterification of a fatty methyl ester (dodecanoate) with b-sitosterol. Using the shift of the $v(C \equiv C)$ stretching mode for the adsorbed propyne species it was possible to determine the strength of the basic sites at the surface of the carbonated oxide: the lower the position of that vibration, the greater the basicity of the corresponding site. A ranking of the basic strength of the surface carbonate species of the lanthanum oxycarbonate samples was thus possible and it was correlated with the catalytic activity: the lower the basicity of carbonates, the higher the phytosterol ester yield [44].

Another protic molecule used to probe basicity is methanol when adsorbed molecularly. Upon accurate spectroscopic analyses (notably by coupling volumetric/IR and gravimetric/IR methods), it enables discrimination 
between molecular and dissociative adsorption of methanol and quantifying the basic sites exposed by a surface [45] $\mathrm{H}_{2} \mathrm{~S}$ has also been used as a hydrogen donor to characterize basicity. For example, infrared analyses on MIL-47 $(\mathrm{V})$ have shown that adsorption of $\mathrm{H}_{2} \mathrm{~S}$ preferentially occurs on $\mu_{2}-\mathrm{O}$ atoms of the $\mathrm{V}=\mathrm{O}$...V entities through hydrogen bonded species. The interaction is weak, with a calculated adsorption enthalpy of $27-29 \mathrm{~kJ} \mathrm{~mol}^{-1}$, revealing that the basicity of these entities is consequently weak [46]. In the case of a NaY zeolite, the high basicity of a few of the oxygen atoms of the supercage was shown by $\mathrm{H}_{2} \mathrm{~S}$ dissociation, leading to the creation of some $\mathrm{OH}$ groups in the supercage only, whereas sodalite cavities (although accessible) remained unaffected [47].

\subsection{Cationic and redox sites}

Hydroxyls complete the coordinative unsaturation of cations. They are therefore, intrinsic probes of the environment and oxydation degree of the moieties bearing them. In some cases, $\mathrm{OH}$ groups can indicate the presence of surface defects and the redox behaviour of a solid. This is particularly true for cerium-based compounds, in which the hydroxyl bands shift according to the presence of $\mathrm{Ce}^{3+} / \mathrm{Ce}^{4+}$ sites and/or oxygen vacancies [48]. The best parallelism to this evidence is provided by methoxy species formed on the activated surface by methanol dissociative adsorption. Methoxys are sensitive to the local environment of cations, so they present specific bands for each cationic species they are coordinated to, and help to describe the surface composition of a material. Moreover, they unravel the oxidation degree of cations and enable a quantification of the concentration of different species present on the surface, as well as the fraction, which can be reversibly transformed by a redox cycle [49-52]. This allows for the identification of mechanistic steps in catalytic reactions, as well as the active sites taking part in them [53].

$\mathrm{CO}$ and $\mathrm{NO}$ are invaluable tools for the characterization of cationic species inside porous compounds. For example, $\mathrm{CO}$ adsorption in Rh-ZSM-5 led to the discovery of a new kind of rhodium gem-dicarbonyls and made possible to understand the mechanism of different catalytic reactions. The shift of the $v(\mathrm{CO})$ vibration showed the Rh position in the porous structure, its oxidation state and the capacity to host different chemical species having different stability, especially in the presence of water [54]. According to this methodology, $\mathrm{CO}$ and $\mathrm{NO}$ adsorption on zeolite-supported $\mathrm{Rh}$ 
nanoparticles containing different promoter elements permitted both characterizing the effect of the additive and the catalytic activity of the noble metal [55].

However, the best application of this methodology is certainly the characterization of copper and iron in porous compounds, since NO probes the $\mathrm{Cu}^{2+}$ and $\mathrm{Fe}^{2+}$ states, while $\mathrm{CO}$ adsorption is more specific to $\mathrm{Cu}^{+}$and, sometimes, $\mathrm{Fe}^{3+}$ states [56-58]. Thanks to the properties of these probe molecules it was possible to study the iron distribution and oxidation state in ZSM-5 [59,6o], FER [61] and Y [62] zeolites, which is of paramount importance for their application in environmental chemistry and petrochemistry. These studies showed that both the oxidation and the coordination states of $\mathrm{Fe}^{2+}$ confined in Ferrierites may change easily, which makes them excellent candidates for active redox sites [61]. Combining $\mathrm{CO}$ and $\mathrm{NO}$ as molecular probes, it was possible to go into the characterization of Fe-FER in very fine detail, identifying the position of iron on three distinct sites inside the crystalline structure [63]. Similarly, the $\mathrm{Fe}^{2+} / \mathrm{Fe}^{3+}$ ratio and distribution in MIL-10o(Fe) were evaluated by combining $\mathrm{CO}$ and NO probes [64] while their role in gas separation was highlighted $[65,66]$.

\subsection{Quantification of sites: coupling IR spectroscopy with thermogravimetry (TGA)}

The quantification of sites by IR spectroscopy is a key point that generally requires the determination of molar absorption coefficients $(\varepsilon)$, which can be measured by progressively adsorbing measured amounts of the probe molecule. However, the discrepancies between the values reported in the literature are worth noting due to a lack of precise control of the amount of probe adsorbed on the sample [67]. One way to overcome this problem is to couple IR spectroscopy and thermogravimetric analysis. In a setup developed in Caen, qualitative as well as quantitative information is obtained simultaneously by combining thermogravimetry and operando IR spectroscopy with online mass spectrometry. The weight (and therefore the number of adsorbed probe molecules) and IR spectra of a solid sample can be analysed simultaneously in real-time operando conditions in a gas flow between room temperature and $773 \mathrm{~K}$. Integrated molar absorbance coefficients can consequently be obtained directly [68]. 


\section{Characterization of zeolites using spectroscopic methods: examples}

\subsection{Acidity in zeolites}

\section{Brønsted acidity in zeolites}

It is generally accepted that Brønsted sites are the most reactive species in the channels and cavities of the zeolites in protonic form. According to Knözinger et al. [69], three wavenumber ranges can be observed in the $\nu(\mathrm{OH})$ stretching region of $\mathrm{H}$-forms of zeolites in the dehydrated state, namely $3745^{-} 375^{\circ}, 3600-365^{\circ}$ and $3530-35^{80} \mathrm{~cm}^{-1}$. The high frequency region has its origin in the presence of terminal silanol groups, which are located at the external surface of zeolite crystallites. The central frequency range $3600-3650 \mathrm{~cm}^{-1}$ is typical of the bridging hydroxyl groups $\mathrm{Si}-\mathrm{OH}-\mathrm{Al}$, responsible of the Brønsted acidity, which are located in large cavities or sufficiently wide pores, where they are unperturbed by interactions with their local environment and accessible to reactant or probe molecules. Finally, the low frequency feature, which typically appears in faujasite-type zeolites, is attributed to perturbed $\mathrm{OH}$ groups which are located in sodalite cages where they are inaccessible to even small probe molecules, such as $\mathrm{CO}, \mathrm{H}_{2}$ or $\mathrm{N}_{2}$.

The concentration and strength of the surface hydroxyl groups responsible for Brønsted acidity in zeolites (that is, both silanols and bridged $\mathrm{Si}(\mathrm{OH}$ ) Al groups) can be determined by adsorption of basic probe molecules monitored by IR spectroscopy. The interaction of the probe basic molecule with the $\mathrm{OH}$ forms an adduct through the acid-base reaction illustrated in Figure 4. The $\mathrm{OH}$ vibrations modes thus differ from the original Brønsted group because the hydrogen bonding perturbation is usually associated with modifications of the hydroxyl vibrational frequencies and minor changes of the internal modes of the bases B.

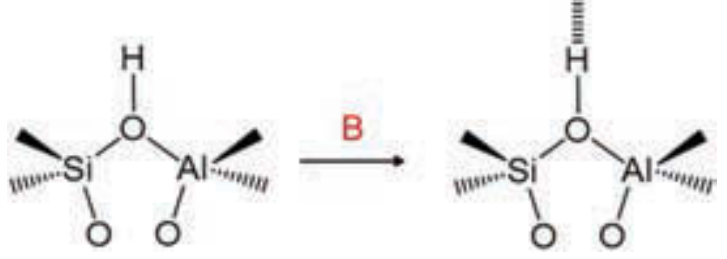

Figure 4. Formation of $\mathrm{ZH}$.... B adducts between a Brønsted acid $\mathrm{OH}$ hosted inside a zeolite channel and $a$ base $B$ via a classical acid-base reaction. 
An illustrative example was reported by Zecchina et al. [70] in which $\mathrm{N}_{2}$ probe molecule induced modifications on the $\mathrm{OH}$ vibration modes of a H-ZSM- 5 zeolite. Upon dosage of $\mathrm{N}_{2}$ (base B), the intensity of the $v(\mathrm{OH})$ mode of the unperturbed Brønsted groups associated with $\mathrm{Si}(\mathrm{OH}) \mathrm{Al}$ gradually decreases while that of the $v(\mathrm{ZH} \cdot \cdots \cdot \mathrm{B})$ vibration simultaneously increases. The observation of an isosbestic point evidences that the $\mathrm{ZH} \cdots \cdot \mathrm{B}$ interaction is really taking place in a stoichiometric manner. At higher pressures, the $\mathrm{Al}-\mathrm{OH}$ groups and finally the silanols groups are also perturbed because of the formation of 1:1 adducts with dinitrogen. Although the interaction of $\mathrm{N}_{2}$ with the structural Brønsted groups is very weak, the induced polarization is sufficient to make the $v(\mathrm{~N}-\mathrm{N})$ modes IR active. The Brønsted acidity of H-ZSM- 5 can be correlated with the magnitude of the redshift of the $\mathrm{OH}$ stretching vibration upon interaction with dinitrogen at low temperature by hydrogen bonding. The shift induced on the $v(\mathrm{OH})$ stretching frequency of $\mathrm{AlOH}$ and of silanols is significantly lower than that on the $\mathrm{Si}(\mathrm{Al}) \mathrm{OH}$ groups, this reflects the fact that hydroxyl groups of structural $\mathrm{Si}(\mathrm{OH}) \mathrm{Al}$ sites are much stronger Brønsted acids than the $\mathrm{AlOH}$ groups and silanols. It should be emphasized that this redshift is proportional to the enthalpy of interaction $(\Delta \mathrm{H})$ of the probe molecule with the protonic site, as has been determined indirectly by calorimetry $[71,72]$. There is no simple relationship between $\Delta \mathrm{H}$ and $v(\mathrm{OH})$, although $\Delta \mathrm{H}$ is considered to be proportional to $[v(\mathrm{OH})]^{1 / 2}$. A series of bases could be used to create a scale with which acids can be compared. This is the so-called BHW method (Bellamy-Hallam-Williams) [67].

Similar conclusions can be obtained when this study is performed using other probe molecules like $\mathrm{CO}, \mathrm{H}_{2}$, ethylene or propene. Upon adsorption of the probe molecule, the $v(\mathrm{O}-\mathrm{H})$ stretching band is redshifted and broadened, with the magnitude of shift related to the acidity of the site. However, the utilization of more basic molecules, like pyridine, methanol, dimethyl ether, ammonia or acetonitrile, provoke stronger $\mathrm{OH}$.... B interactions, even protononic transfers. In these cases, the IR spectra obtained are more complex due to the presence of Fermi resonance effects $\left[73^{-75}\right]$. Fermi resonances generally arise when two vibration modes with similar symmetry have comparable energies. As a consequence, the two original modes appear combined and lead to two different bands, each of which is a mixture of the original modes [73]. When the interaction $\mathrm{OH} \cdots . \mathrm{B}$ is strong, the first harmonic of the $\delta(\mathrm{OH})$ vibration (in-plane deformation) is very close to the $\nu(\mathrm{OH})$, creating a so-called Evans' window [67,76] (Figure 5a). Furthermore, the $v(\mathrm{OH})$ band broadens and shifts to lower wavenumbers, eventually overlapping 

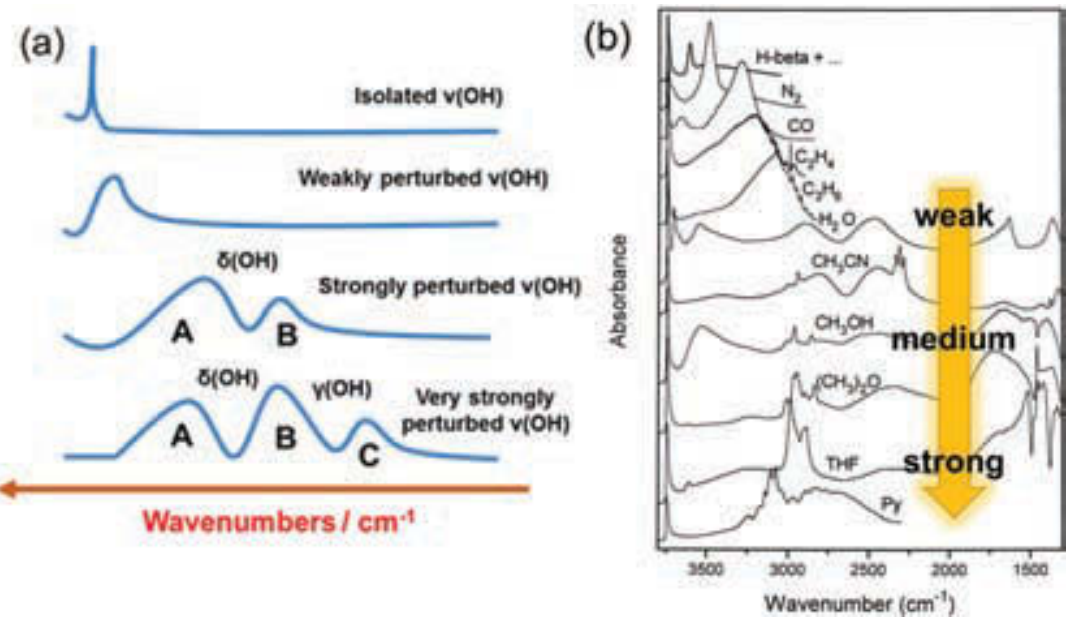

Figure 5. a) Evans' window on a $v(\mathrm{OH})$ vibration in the cases of free $v(\mathrm{OH})$ and $v(\mathrm{OH})$ perturbed by a $\mathrm{H}$-bond, strong $\mathrm{H}$-bond, and very strong $\mathrm{H}$-bond. b) Comparison of the background subtracted IR spectra of H-Beta/B adducts. Adapted with permission from [74]. Copyright 1997, American Chemical Society

with the two $\delta(\mathrm{OH})$ and two $\gamma(\mathrm{OH})$ harmonics, themselves shift to higher wavenumbers by the $\mathrm{H}$-bonding. The band structure observed is denoted as an A, B, C system and is indicative of a very strong H-bonding [76]. This reveals that the interaction has become sufficiently strong to shift the $\delta$ vibration modes out of the range of the framework vibrations. On the basis of these considerations we can now understand the sequence of spectra in Figure $5 \mathrm{~b}$, which correspond to the interaction of a series of bases (increasing the basic character from $\mathrm{N}_{2}$ to pyridine) with zeolite $\mathrm{H}-\beta[74,77]$. A gradual shift to lower frequencies of the broad absorption associated with the perturbed $\nu(\mathrm{OH})$ as well as the formation and evolution of $\mathrm{A}, \mathrm{B}, \mathrm{C}$ features as a function of the basic character of the probe molecule emerges. It can also be noted that for THF and pyridine the shift is slightly smaller because the proton was transferred to the nucleophilic probe molecule. Similar observations have been obtained for other zeolites such as H-MOR or ZSM-5 [78].

The choice of probe molecule is crucial to obtain an overall view of the acidity. Its size has to be small enough to interact with all available sites and to avoid confinement effects but its basic strength has to be strong enough to interact even with the weakest acidic sites. Ammonia seems to be a good candidate for this but due to the high polarity of the $\mathrm{NH}$ bonds, hydrogen bonding with basic entities governs the coordination of adsorbed species and direct conclusions about acid strength are not straightforward. That is 

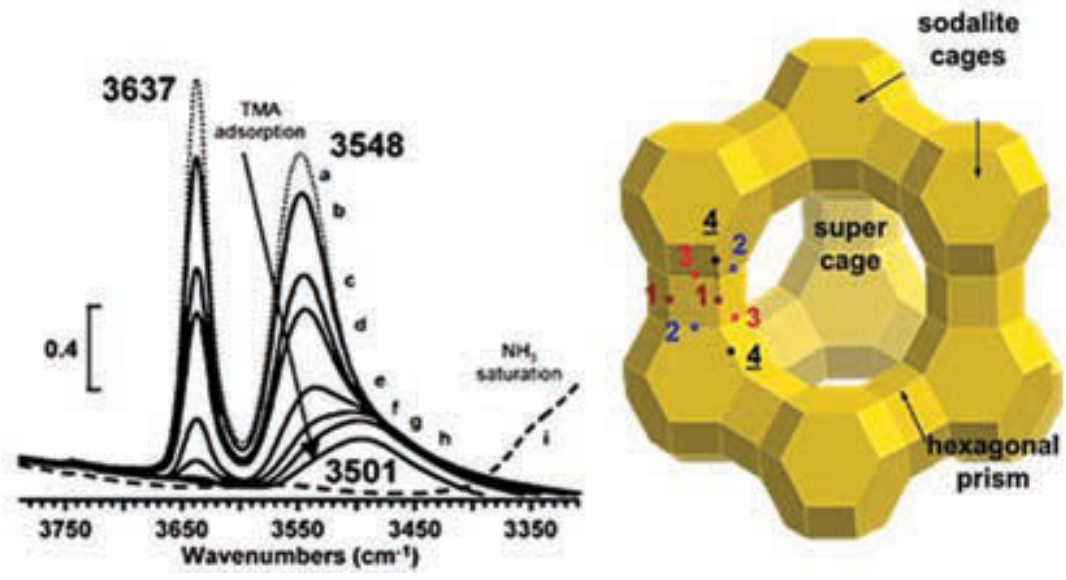

Figure 6. IR spectra of the $\mathrm{HY}$ zeolite upon TMA adsorption and $\mathrm{NH}_{3}$ saturation evidencing hydroxyls in the supercages at $3637 \mathrm{~cm}^{-1}$, in the sodalite units at $3548 \mathrm{~cm}^{-1}$ and in the hexagonal prism at $3501 \mathrm{~cm}^{-1}$. Adapted with permission from [32]. Copyright 2005, American Chemical Society

why the adsorption of several probe molecules is often required [35]. As an example, the FAU and the MOR structures are made of larger and small cavities in which some acidic hydroxyls are out of reach for basic molecules such as pyridine. The co-adsorption of the strongly basic trimethylamine (TMA) and ammonia (Figure 6) give an IR evidence of three kinds of acidic hydroxyls in defect-free HY zeolites [31,32]. Moreover, the TMA desorption is associated with the recovery of hydroxyls at 3656 and $3638 \mathrm{~cm}^{-1}$. The two corresponding $v(\mathrm{~N}-\mathrm{H})$ bands reveal the presence of at least two distinct acidic strengths for the hydroxyls located inside the supercages. For the same site location, the local chemical factor should then play a role: aluminium distribution in the framework is not necessarily homogeneous, and the number of $\mathrm{Al}$ next-nearest neighbours influences the acidic strength of a given site. Another explanation for the unusual $3656 \mathrm{~cm}^{-1}$ component could be that part of the $\mathrm{O}_{4}$ crystallographic site is a proton holder for this $\mathrm{HY}$ zeolite with low $\mathrm{Si} / \mathrm{Al}$ ratio. In such cases, all the four theoretically forecasted sites in the zeolitic FAU structure (Figure 6) would have been observed by IR spectroscopy [32]. The combined use of these two molecules also helped us to better characterize the various coordinated $\mathrm{NH}_{4}^{+}$and to determine the activity ranking between ammonium species and coordinated ammonia over Lewis sites during $\mathrm{NO}_{\mathrm{x}}$ selective reduction.

\section{Lewis acidity in zeolites}

The origins of Lewis acidity in zeolites are diverse and depend on the structure and chemical composition of the zeolite material under investigation 
[79,80]. From a general point of view, three types of Lewis acid centres in zeolites can be distinguished: i) charge-balancing extraframework alkali cations $[69,73,81,82]$, ii) extraframework aluminum species located in defect centres [83-85], and iii) heteroatoms isomorphically substituted in the framework [86-91]. No direct observation of any vibration band by IR spectroscopy for Lewis acid sites is possible. Nevertheless, the influence of the acid site on a probe molecule will provide information on the Lewis acid site by IR spectroscopy [67]. CO is the probe molecule most widely used for characterizing Lewis acidity in zeolites [92], although other basic molecules such as methanol, amines, or pyridine also give relevant information [93-96].

Charge-balancing cations such as the monovalent alkali cations, other than $\mathrm{H}^{+}$, may be considered Lewis acid sites [81]. These cations generate strong electric fields within the zeolite cages or channels and are capable to polarize the probe molecule admitted when they are located in accessible sites. For instance, $\mathrm{CO}$ can interact with the exchangeable cations in zeolites shifting the $\mathrm{C}-\mathrm{O}$ stretching frequency to higher values than that in the gas phase $\left(2143 \mathrm{~cm}^{-1}\right)$ through an interaction via the carbon atom [97]. Knözinger et al. [69] reported a linear correlation between the ionic radius of the alkali metal exchanged and the shift of $v(\mathrm{CO})$ for the series of zeolites LiY, NaY, KY, RbY and CsY. As illustrated in Figure 7 , the frequency shift $\Delta v(\mathrm{CO})$ clearly decreases when increasing the cation radius, LiY showing the strongest Lewis acidity. This suggests an electrostatic interaction with

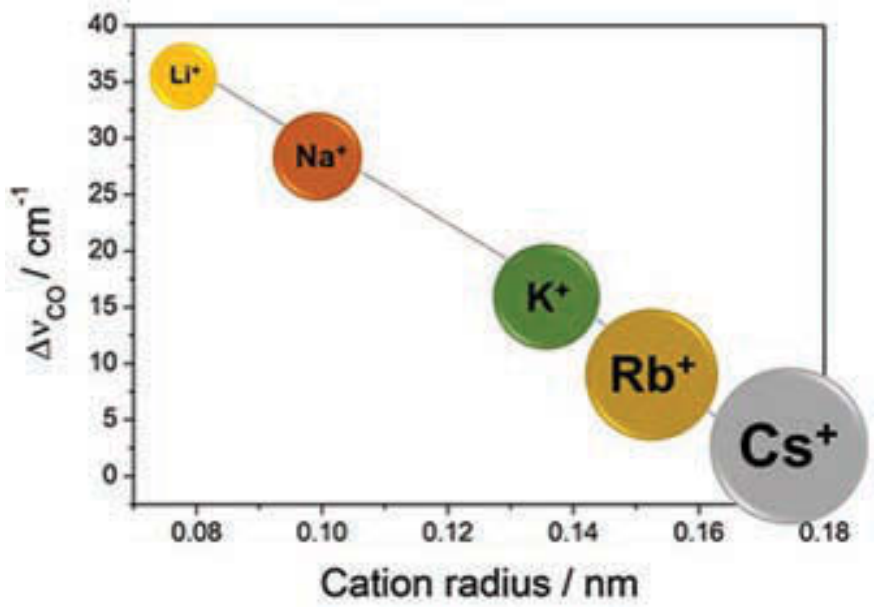

Figure 7. Interaction of CO with exchangeable alkali metal cations in Y-zeolite: correlation of C-O stretching frequency shift with cation radius. 
the electric field strength $(\mathrm{F})$ determining the frequency shift. In a similar study, Otero-Areán et al. [92] reported that, besides the fundamental $\mathrm{C}-\mathrm{O}$ stretching mode, weaker band appears at $90-140 \mathrm{~cm}^{-1}$. This band can be assigned to the combination mode between the frequency of $v(\mathrm{CO})$ and the cation-carbon bond vibration. The authors observed this band (at $139 \mathrm{~cm}^{-1}$ ) for CO adsorbed on Na-Y by using far IR radiation from a synchrotron source. Observation of the combination mode is relevant to zeolite characterization by IR spectroscopy, since the characteristic cation-carbon stretching vibration is very sensitive to the specific cation present in the zeolite.

The presence of Lewis acidity in protonic zeolites is usually attributed to the presence of extraframework Al-containing species (EFAL) [98-101]. The structure of a true Lewis acid site is still controversial although it could be associated with trigonal $\mathrm{Al}$ atoms formed as a result of zeolite dehydroxylation by thermal treatment or leached from the zeolite framework during chemical treatment [101-105]. In fact, the presence of Lewis acidity for zeolites rich in extraframework $\mathrm{Al}$ species is well detectable by IR spectroscopy of adsorbed probe molecules. Catana et al. [79] identified three types of Lewis acid sites by FTIR of CO adsorbed at low temperature and the relative intensities of these peaks were correlated with the structure type and extraframework $\mathrm{Al}$ amount. In this study they used different methods to create Lewis acid sites in a controlled way. Alumination with $\mathrm{AlCl}_{3}$ leads to well-distributed extraframework $\mathrm{Al}$ species with a highly distorted geometry, which act as strong Lewis acid sites. A mild steaming procedure leads to similar sites and a high concentration of extraframework Al. Although high, the amount of $\mathrm{Al}$ extracted from the framework with a severe steaming procedure is less effective in creating strong Lewis acid sites, probably because the clustered $\mathrm{Al}$ species block the access of the probe molecules to the active sites.

The incorporation of trivalent ion such as $\mathrm{Al}^{3+}, \mathrm{B}^{3+}, \mathrm{Ga}^{3+}, \mathrm{Fe}^{3+}$ or $\mathrm{In}^{3+}$ in the silica framework creates one negative charge in the zeolite lattice, which is balanced by a counter-ion, usually a proton [106]. As was mentioned in the previous section for the case of $\mathrm{Al}$, the bridging hydroxyls associated to the $\mathrm{Si}(\mathrm{OH}) \mathrm{M}^{3+}$ group are responsible of the Brønsted acidity. Many works subsituting aluminum by B, Fe or Ga have been published and this practice affects directly the properties of the bridging hydroxyls. On the other hand, when a tetravalent cation $\left(\mathrm{Ge}^{4+}, \mathrm{Sn}^{4+}, \mathrm{Ti}^{4+}\right)$ substitutes a Si atom of the framework, the zeolite lattice remains neutral due to the identical charges and no Brønsted acid sites are generated, although this substitution could directly affect the properties of an $\mathrm{OH}$ group connected to the heteroatom [107]. 
By contrast, strong acid Lewis sites can be formed upon thermal induced migration of heteroatoms $\left(\mathrm{Al}^{3+}, \mathrm{B}^{3+}, \mathrm{Ga}^{3+}, \mathrm{Ti}^{4+}, \mathrm{Sn}^{4+}\right)$ from the framework into partial or total extraframework positions, generating "defect sites". The formation of these centres is favoured by the presence of water vapour in the gas phase during the thermal treatments at high temperature $[70,75]$. In a few cases, "defect sites" are detected in the IR spectrum of activated samples by specific IR bands, mainly in the low frequency range: bands situated at $3782 / 880 \mathrm{~cm}^{-1}$ on $\beta$-zeolite [108] and around $960 \mathrm{~cm}^{-1}$ on Ti-silicalite [109], that can be considered as a fingerprint of Lewis-acid sites.

\subsection{Basicity in zeolites}

Zeolites intrinsically possess Lewis basic sites linked to the framework oxygen atoms bearing negative charge, which increase as the framework $\mathrm{Al}$ content increases [110]. For a given $\mathrm{Si} / \mathrm{Al}$ ratio, the negative charge on the oxygen atoms is higher the more electropositive, (or the less electronegative) the charge-balancing extraframework cations are. For instance, considering the series of alkaline cations the basicity of the zeolite increases in the order: $\mathrm{Li}^{+}<\mathrm{Na}^{+}<\mathrm{K}^{+}<\mathrm{Rb}^{+}<\mathrm{Cs}^{+}[110,111]$. Although the framework oxygen atoms are the most characteristic basic sites in zeolites, other basic centres can be found in zeolites as well, such as hydroxyl groups resulting from the dissociation of water in hydrated extraframework cations [112] or basic oxygen atoms in oxide clusters in the pores [113]. In alkaline forms of zeolites, only the centres associated with regular or strained oxygen bridges of the $\mathrm{Si}-\mathrm{O}-\mathrm{Al}$ type are expected to exist.

The determination of the basicity of a zeolite involves estimating the number and strength of these basic centres. As in the case of acid sites, basic sites can be identified adsorbing probe molecules, although in this case acid probe molecules, such as $\mathrm{CO}_{2}$, pyrrole, methanol, acetonitrile, acetylene, halogenated alkanes, $\mathrm{H}_{2} \mathrm{~S}, \mathrm{NO}$ and $\mathrm{N}_{2} \mathrm{O}_{4}[37,110,114,115]$ are required. An ideal acidic probe molecule should interact exclusively with the zeolite basic lattice oxygen. However, the compensating alkaline cations act as Lewis acid sites and form conjugated acid-base pairs, which can interact with any molecule. An ideal probe molecule for zeolite basicity should adsorb selectively on basic lattice oxygen atoms and not induce any modifications in the solid. In this sense, the best molecules are those which disproportionate into cations and anions. The anions immobilize the exchangeable cations. The cations adsorb onto the lattice oxygen of the zeolitic framework and probe the basicity of this oxygen. 
Acetylene and its derivatives also turned out to be suitable probemolecules for basic centres in zeolites. Acetylene exhibits shifts in $v(\mathrm{C}-\mathrm{H})$ frequency, which are sensitive to the strength of basic sites of alkaliexchanged zeolites. Uranova et al. [115] studied the adsorption of acetylene on $\mathrm{NaX}, \mathrm{Cs} / \mathrm{NaX}$, and $\mathrm{Na} / \mathrm{Y}$ zeolites. Two types of complexes with acetylene may be formed: i) complexes with metal cations (complex 1) and ii) complexes with basic oxygen atoms of the framework (complex 2). One can expect that the frequency of the stretching vibrations will slightly increase in the case of complex 1, whereas the opposite shift of this band may be anticipated in the case of complex 2. The decrease in frequency of the stretching vibrations in such complexes compared to the gas phase $\left(3287 \mathrm{~cm}^{-1}\right)$ may be accounted for by the weakening of the $\mathrm{C}-\mathrm{H}$ bond in the complex involving basic oxygen atoms. Therefore, this frequency may be used as a tool for estimating the basic strength of surface oxygens. Thus, the $v(\mathrm{C}-\mathrm{H})$ frequency decreases from $3216 \mathrm{~cm}^{-1}$ for NaM and $3205 \mathrm{~cm}^{-1}$ for $\mathrm{NaY}$ zeolites, to $3175^{-} 3185 \mathrm{~cm}^{-1}$ for $\mathrm{NaX}$ and $\mathrm{Cs} / \mathrm{NaX}$ zeolites, indicating a strengthening of the basic centres in X-type zeolites. Lavalley et al. [116] proposed the use of but-1-yne and showed that this probe could be used for zeolites with moderate basicity such as $\mathrm{Na}-\mathrm{Y}$ or Na-X zeolites and could be more sensitive to the heterogeneity of basic sites than other probe molecules.

Other probe molecules have also been used for the characterization of basicity in zeolites. For example, $\mathrm{H}_{2} \mathrm{~S}$ was used for characterising faujasite type zeolites, such as $\mathrm{NaX}$ and $\mathrm{NaY}$. The adsorption depends on their Si/Al ratio. Protons, which were generated via dissociation of $\mathrm{H}_{2} \mathrm{~S}$, attacked the zeolite lattice and formed new $\mathrm{OH}$ groups. On $\mathrm{NaY}$ with a $\mathrm{Si} / \mathrm{Al}$ ratio of $c a$. 2.5 or higher, no $\mathrm{H}_{2} \mathrm{~S}$ dissociation occurred, suggesting a weak basicity $[37,117,118]$. More recently, the disproportionation reaction of $\mathrm{NO}_{2}$, leading to a nitrate anion and a $\mathrm{NO}^{+}$cation (nitrosonium), has been used to characterize the basicity of alkali-exchanged FAU zeolites. The nitrate ions are stabilized by extraframework cations, whereas $\mathrm{NO}^{+}$directly interacts with framework oxygen atoms. The $\nu\left(\mathrm{NO}^{+}\right)$stretching frequency shift is sensitive to the electron density of the oxygen atom framework and, consequently, provides information about the basicity of the zeolite [39].

\subsection{Redox properties: metal cation exchanged zeolites}

Numerous metal transitions, noble metals and rare-earth cations have been extensively used as charge-balancing metals in zeolites. Significant efforts have been dedicated to the spectroscopic characterization of these 
materials aimed at understanding the nature (oxidation state, location, coordination environment, etc.) of the active metal sites in different zeolite structures. The redox properties of these materials are very important for their catalytic performance in numerous reactions like the selective catalytic reduction (SCR) of nitrogen oxides with hydrocarbons [35]. Below, we discuss as case study where a Co-containing zeolite shows the potential of IR spectroscopy for the characterization of metal transition sites in zeolites.

The co-adsorption of $o$-toluonitrile (oTN) and nitrile (NO) allowed the identification of different $\mathrm{Co}^{\mathrm{n}+}$ species and their location in a CoH-MFI zeolite [33]. Significant amounts of cobalt species were located on the external surface, mostly in the form of divalent cobalt, whereas on the internal surface the predominant Co species were trivalent and divalent ions. These observations were very valuable for explaining the reactivity of methane-SCR reaction. The $\mathrm{Co}^{3+}$ species active sites were located in the cavities, although probably in non-classical cation positions, characterized by a nitrosyl $\nu(\mathrm{NO})$ band at $1930 \mathrm{~cm}^{-1}$. These are able to convert $\mathrm{NO}$ to an adsorbed bridging nitrate species, which can be later decomposed to yield gas phase $\mathrm{NO}_{2}$ [119]. The cavity may contribute to the stabilization of aggregates containing trivalent cobalt. At the same time, the presence of cobalt-isocyanates involved in the SCR suggests that a possible route for the reaction implies the reduction of nitrate-like species by methane, forming water and isocyanates, which could later react with $\mathrm{NO}$ producing $\mathrm{N}_{2}$ and carbon dioxide. On the contrary, it seemed that substitutional $\mathrm{Co}^{2+}$ ions did not play a key role in the reaction, being almost certainly "redox-inactive". $\mathrm{Co}^{2+}$ dinitrosyls formed on them being decomposed well below the reaction temperature, they did not seem to be involved in the reaction [119]. These considerations link the active site with the reactivity of the species coordinated on it and the possible intermediates for the SCR reaction.

\section{Characterization of MOFs using spectroscopic methods: examples}

Metal-organic frameworks (MOFs) are characterization porous materials consisting of metal ions or clusters linked by polydentate organic linkers forming $3 \mathrm{D}$ structures with very high porosity and specific surface area $[120,121]$. The diversity of metals and organic ligands that can be combined to form MOFs is huge, with more than 20000 compounds of this class already reported in the literature [122]. Modifications of metal and/or organic linkers allows for changing the properties, size and shape of the pores. 
Moreover, the introduction of guest species into the pores, which also modify the MOF properties and the type of active sites, is possible. These factors make MOFs very versatile compounds that may be potentially applied in different fields such as gas adsorption [123-125], molecular separation $[126,127]$, or catalysis $[128,129]$, among others $[130,131]$, as will be discussed later on in this book.

The basic techniques used for MOF characterization are similar to those used for other materials, namely, $\mathrm{XRD}, \mathrm{N}_{2}$ adsorption/desorption, thermogravimetric analyses, NMR and SEM. XRD, which allow us to determine the crystallinity and phase of the material. The surface area and porosity are calculated from the $\mathrm{N}_{2}$ adsorption/desorption isotherms and thermogravimetric. Analyses inform on the thermal stability of the compound. Studies by SEM are useful to determine crystal size and morphology of the solid particles. As stated in the introduction, EXAFS and XANES spectroscopies are also used to determine the local environment of the sites. This data may be completed with information about the oxidation state of the metal obtained from UV-visible spectroscopy. Thanks to the development of infrared spectroscopy and its use in the characterization of other materials, IR occupies a relevant place in the study of active sites in MOF structures. In addition, this technique is used to determine their behaviour when exposed to certain reactive molecules. This is especially important in the field of catalysis. Hence, in this part we will focus on infrared spectroscopy, commenting on some of the most relevant works on MOF characterization using this technique.

The active sites in MOFs can be the metallic ions or clusters, the functional groups in the organic linkers or guest species into the pores. The aspects most studied by IR spectroscopy are thus: i) the organic linkers, ii) the metallic ions or clusters, and iii) the acid-base properties. The organic linkers, structural components in MOFs, are characterized by analysis of the direct IR spectra, while the study of metallic centres and acid base properties require the adsorption of probe molecules in a similar way to the metallic oxides or zeolites. Accordingly, the discussion of examples has been divided into "direct IR analysis" and "adsorption of probe molecules".

\subsection{Direct IR analysis}

The direct analysis of the IR spectra permits observation of the presence of organic molecules interacting (or not) with the metallic sites and hydroxyl groups in the MOF structure [132]. Therefore, this technique is widely used 
in the characterization of MOF compounds and it allows confirmation of the synthesis of the desired compound. Furthermore, the potential of this technique makes it adequate for application in other cases.

For instance, Xue et al. [132] were interested in developing catalysts for the cycloaddition of $\mathrm{CO}_{2}$ and prepared a gadolinium-based MOF with PMDA (pyromellitic dianhydride) as an organic linker instead of the aromatic carboxylic acid usually used in this synthesis. The product obtained was characterized by conventional techniques (DRX, $\mathrm{N}_{2}$ adsorption, TEM...) and the IR spectra of the pure organic linker and prepared MOF were compared. The spectrum of PMDA revealed two bands at 1563 and $1368 \mathrm{~cm}^{-1}$, attributed to the asymmetric and symmetric stretching vibrations of carboxylate groups in the linker used. The formation of chemical bonds between the carboxylate groups in the PMDA and Gd(III) sites implies a modification of the carboxylate symmetry. Consequently, the shift of these bands to closer wavenumbers in the synthesized MOF confirmed the interaction metal-linker in the synthesized compound.

Among the most studied metal-organic frameworks, we find UiO, MIL-53 and MIL-10o families. Zr-based UiO are particularly interesting for their high thermal stability, which is of great importance as catalysts or absorbents in applications. These potential applications motivated the study of different aspects of the compounds. One such example is the work by Liang et al. on UiO-66 $\left(\mathrm{NH}_{2}\right)$ [133]. UiO-66 shows good activity in photocatalysis, comparable to inorganic standard photocatalysts. However, an improvement on its absorbance is required. In order to obtain an improved photocatalyst, the combination of UiO-66- $-\mathrm{NH}_{2}$ and zinc phthalocyanine (a typical organic conductor) by a condensation reaction was studied in this work. The metallic clusters were octahedral $\mathrm{Zr}_{6} \mathrm{O}_{4}(\mathrm{OH})_{4}$ units, with the edges of the octahedron bridged by carboxylates from dicarboxylic acid BDC-NH (2-amino-1,4-benzenedicarboxylic acid), which acted as an organic linker in this compound [134] (Figure 8). The reaction between UiO-66 $\left(\mathrm{NH}_{2}\right)$ and phtalocyanine was followed by IR spectroscopy. After reaction, the disappearance of the IR band typical of $-\mathrm{NH}_{2}$ groups (1030 and $1130 \mathrm{~cm}^{-1}$ ) was observed and the appearance of new bands at 1620 and $3344 \mathrm{~cm}^{-1}$ attributed to $\mathrm{CO}-\mathrm{NH}_{2}$ and N-H stretched respectively, confirming the incorporation of the phtalocyanine to the MOF structure by an amide bond to the linker.

Continuing with the UiO family, we analyse the behaviour of hydroxyl groups using direct IR spectroscopy next. Besides a high thermal stability, the creation of coordination vacancies, which act as Lewis acid sites, during dehydration, makes the $\mathrm{UiO}$ family a very good candidate for use 


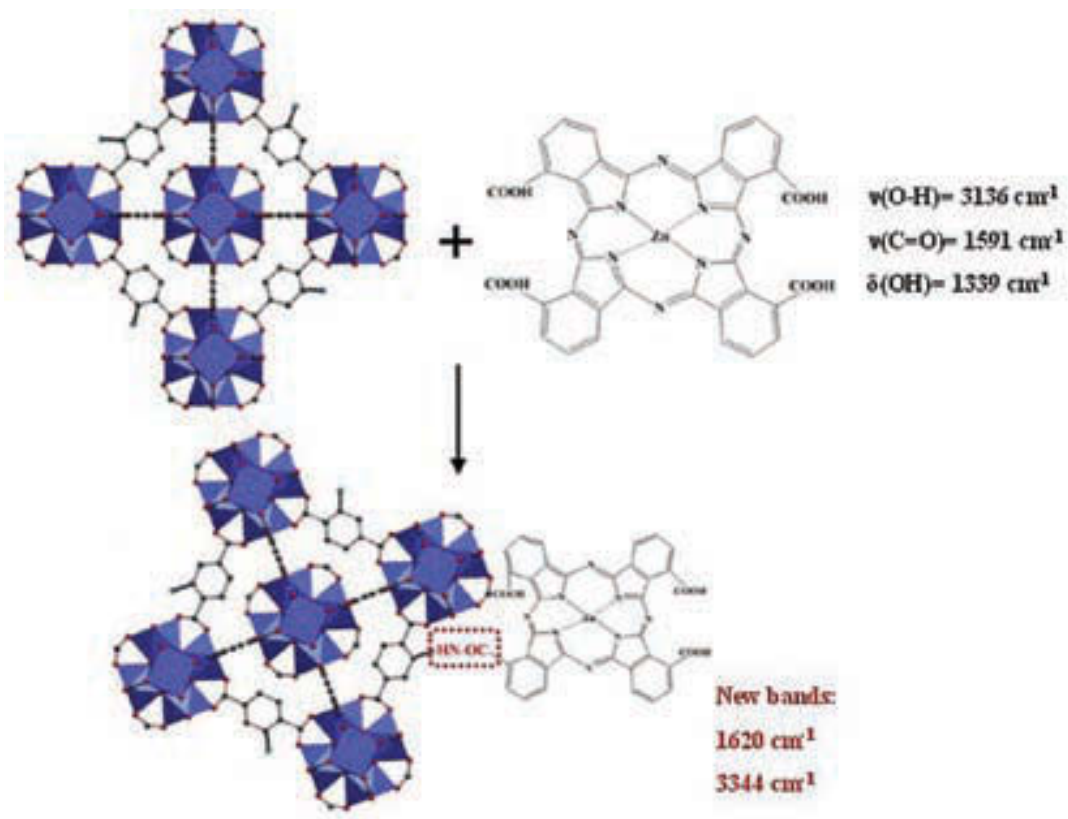

Figure 8. Combination of UiO-66- $\mathrm{NH}_{2}$ and zinc phthalocyanine. Adapted with permission from [134]. Copyright 2008 American Chemical Society.

in catalysis. This motivated the study by Shearer et al. [135]. In this work, a combined DRIFTS-TG analysis permitted the determination of the $\mathrm{OH}$ species implied in the dehydration process of UiO-66 and UiO-67. The authors detected only one band at $3681 \mathrm{~cm}^{-1}$ in the dehydrated UiO-67 sample, in agreement with the structure of the $\mathrm{Zr}_{6} \mathrm{O}_{4}(\mathrm{OH})_{4}$ units and the symmetrical $\mathrm{OH}$ distribution in the cluster. However, in the sample UiO-66, constituted by similar cornerstones, the hydroxyl region of the spectrum shows a high complexity and at least six $\mathrm{OH}$ bands appear during the dehydration process. The authors explain the observed differences between both samples by the presence of $\mathrm{Cl}^{-}$ions coming from the synthesis. The $\mathrm{Cl}^{-}$may replace some $\mathrm{OH}$ groups resulting in a lower symmetry of hydroxyls. These results point to an influence of the organic linker on the behaviour of the resulting compound.

\subsection{Adsorption of probe molecules}

CO adsorption monitored by IR spectroscopy is the most widely used method to obtain information on the acid sites strength of metallic oxides, 
zeolites, and MOFs [12,136,137]. The interaction of a weakly acid molecule like $\mathrm{CO}$ with the $\mathrm{H}$-atom from the hydroxyl group results in an elongation of the $\mathrm{O}-\mathrm{H}$ bond and, consequently, a shift of the $\mathrm{v}(\mathrm{OH})$ vibration mode to lower wavenumbers. The extent of the shift is indicative of the $\mathrm{OH}$ acidity [138]. $\mathrm{N}_{2}$ has frequently been used as probe molecule because it is an IR inactive molecule (has no dipolar moment) and it does not interact with the active site, so its perturbation is only attributed to electrostatic interactions, especially important in the channels of porous materials such as zeolites [139].

Among the most widely studied MOFs we find M-MIL-53, where M is a trivalent metallic cation. The structure of this compound is constituted by octahedral $\mathrm{MO}_{6}$ units whose corners are connected (via $\mathrm{OH}$ ) by 1,4-benzenedicarboxylate (Figure 9) [140-142]. Mihaylov et al. [143] studied in detail the hydroxyls region of the IR spectra of a MIL-53 (Al) series by CO and ${ }^{15} \mathrm{~N}_{2}$ adsorption. Structural $\mu_{2}-\mathrm{OH}$ species absorbing at $3707 \mathrm{~cm}^{-1}\left(3704 \mathrm{~cm}^{-1}\right.$ by Ravon et al. [144]) were observed. Two shoulders at lower frequencies were assigned to $\mathrm{OH}$ interacting via weak $\mathrm{H}$-bond with the framework or

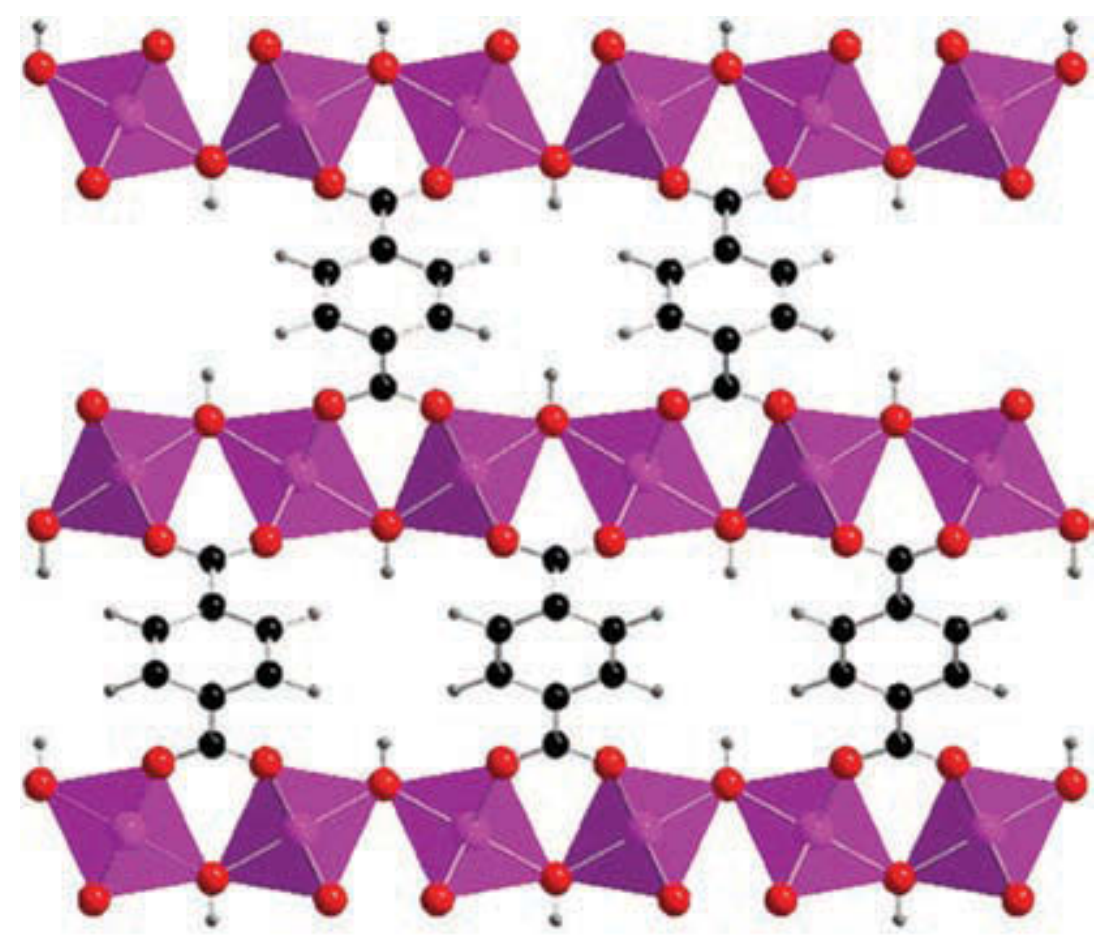

Figure 9. The local M environment within MIL-53. Adapted with permission from [94b]. Copyright 2013 American Chemical Society. 
with the rest of the acid used in the synthesis. These authors demonstrated the huge importance of this situation on the quantification of $\mathrm{OH}$ acid strength. The interaction via H-bond of hydroxyl groups with the framework provokes a shift to lower frequencies in the initial spectrum of the sample and the measured shift after $\mathrm{CO}$ adsorption does not correspond to the real situation. The so-called H-bond method, used in this work, permits calculation of the proton affinity $(\mathrm{PA})$ from the $\Delta \nu(\mathrm{OH})$ measured after $\mathrm{CO}$ adsorption at $100 \mathrm{~K}$ according to the following equation:

$$
P A^{O H}=P A^{S i O H}-442.5 \log \left(\frac{\Delta v(O H)}{\Delta v(S i O H)}\right)
$$

where $\mathrm{PA}^{\mathrm{OH}}$ and $\mathrm{PA}^{\mathrm{SiOH}}$ are the proton affinities of a specific $\mathrm{OH}$ in the sample, corresponding to a silanol group (taken as reference), respectively. The interaction via $\mathrm{H}$-bond observed in the initial spectrum of the sample, provokes a deviation of the measured values from the real ones. Therefore, it is very important in this type of solids to calculate the intrinsic $\mathrm{OH}$ frequency to obtain the correct values of the induced CO shift. In this way, calculation of proton affinities using the equation above will provide the correct values of this parameter.

The influence of the metal on the acid properties of MIL-53 was also studied by $\mathrm{CO}$ adsorption at low temperature on MIL-53 (Al) and MIL-53 (Ga) [144]. The experimental observations showed a small shift to lower frequencies of $\nu(\mathrm{OH})$ after $\mathrm{CO}$ adsorption at $100 \mathrm{~K}: 30-5 \mathrm{O} \mathrm{cm}^{-1}$ for MIL-

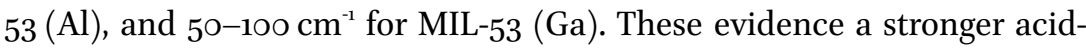
ity of the Ga-containing MOF. The authors also detected a difference between the measured shift of $v(\mathrm{OH})$ vibration mode and the one calculated by DFT. Moreover, molecular modelling evidenced that $\mathrm{OH}$ groups in the Al-containing MOF are straight, while tilted $\mathrm{OH}$ are present in MIL-53 (Ga). This characterization was used to explain the observed activity in the Friedel-Crafts alkylation reaction. The low activity observed using MIL-53 (Al) was related to its low acidity. However, the acid strength alone cannot explain the high activity of MIL-53 (Ga). The authors attributed the high catalytic activity of this compound to a strong stabilization of the reaction intermediate by the tilted $\mathrm{OH}$ groups in the Ga-MOF supported by theoretical calculations.

The flexibility of MOF structures is among the most important properties of these solids. It depends on several factors but the most important one is the nature of the metal [145]. Hence, Nouar et al. [145] studied MIL-53 (Fe-Cr), and the results were compared to those for MIL-53 (Fe) and MIL-53 (Cr). The analyses of the $950-800 \mathrm{~cm}^{-1}$ region evidenced the 
presence of bands at $847 \mathrm{~cm}^{-1}$ and $928 \mathrm{~cm}^{-1}$ for the compounds containing $\mathrm{Fe}$ and $\mathrm{Cr}$, respectively. These bands, sensitive to $\mathrm{H}_{2} / \mathrm{D}_{2}$ exchange, were attributed to $\delta(\mathrm{OH})$ modes. In the bimetallic sample, besides these bands, a new band at $885 \mathrm{~cm}^{-1}$ was observed. Through comparison of the spectra, this new band was attributed to $\mathrm{OH}$ bridged to both metals $(\mathrm{Cr}$ and $\mathrm{Fe}$ ), demonstrating the interaction between both metals. $\mathrm{CO}_{2}$ adsorption isotherms evidenced that the presence of Fe-Cr interaction strongly modifies the behaviour of the solid to the point that it does not match the expected behaviour for a theoretical mixture of monometallic compounds. Additionally, MIL-53 ( $\mathrm{Fe})-\mathrm{X}\left(\mathrm{X}=\mathrm{CH}_{3}, \mathrm{Cl}, \mathrm{Br}\right)$ were characterized by propyne adsorption. This probe molecule, containing acid and base functions, may be used to detect the presence of acid-base pairs in the solid. The $\mathrm{C} \equiv \mathrm{C}$ bond acts as proton acceptor and the function $\equiv \mathrm{C}-\mathrm{H}$ group as proton donor.

In the case of the MIL-10o family characterized by CO adsorption, we note the work by Vimont et al. [9]. The hydroxyls region of MIL-10o at different states of hydration was analysed. After a treatment at high temperature only one band at $3585 \mathrm{~cm}^{-1}$ was observed. It shows $\mathrm{OH}$ bonded to the $\mathrm{Cr}^{3+}$ sites and demonstrates that this type of $\mathrm{OH}$ is present in the MOF structure. At a higher hydration degree (lower temperature of treatment), this $\mathrm{OH}$ is perturbed, which points to some Brønsted acidity in this $\mathrm{OH}$. Accordingly, measurements of Brønsted acidity by $\mathrm{CO}$ adsorption were carried out. The results show a shift of the hydroxyl band from $3585 \mathrm{~cm}$ ${ }^{1}$ to $3495 \mathrm{~cm}^{-1}\left(\Delta v=90 \mathrm{~cm}^{-1}\right)$ after interaction with the $\mathrm{CO}$ molecules, thus concluding that $\mathrm{Cr}-\mathrm{OH}$ sites have an acid strength similar to that of $\mathrm{Si}-\mathrm{OH}$ groups. The $\mathrm{CO}$ adsorption at higher hydration degree indicated a weaker acidity of the water molecules interacting with the $\mathrm{Cr}-\mathrm{OH}$. Moreover, the $\mathrm{CO}$ adsorption permitted characterization of the Lewis acid sites. Three bands at 2192, 2200 and $2184 \mathrm{~cm}^{-1}$ were detected, which suggested a high heterogeneity of Lewis acid sites in this solid.

Gas separation and storage are among the most studied applications of MOFs. In this sense, it is worth noting the work about $\mathrm{H}_{2}$ storage and $\mathrm{CO}_{2}$ adsorption on M-MOF-74 (M=Mg, Mn, Fe, Co, Zn) [123] by Fitzgerald et al. CPO-27-M. Spectra recorded after $\mathrm{CO}_{2}$ adsorption on every solid at different pressures and temperatures were compared. The $v_{3}$ vibration (symmetric stretching mode of $\mathrm{CO}_{2}$ ) seems to be the most sensitive to the gas-solid interaction and was related to the interaction strength due to electrostatic and charge transfer effects, which were different for each metal. This study evidences one more time versatility in tuning the properties of MOFs, in this case, the interaction with $\mathrm{CO}_{2}$. 
With regard to the importance of operando techniques in spectroscopy, Wuttke et al. used operando IR spectroscopy to clarify the separation mechanism of propane/propene mixtures [65]. Observation of the surface material during the separation of both hydrocarbons evidenced that $\mathrm{Fe}(\mathrm{II})$ sites, thanks to their ability to interact with the double bond of the olefin, hold the main responsible for the separation. Propane adsorption on the MOF generated two bands at 2868 and $2958 \mathrm{~cm}^{-1}$, attributed to $2 \delta\left(\mathrm{CH}_{3}\right)$ and $v\left(\mathrm{CH}_{3}\right)$, respectively, while the interaction of propene with the solid was characterized by the presence of $\nu\left(\mathrm{CH}_{3}\right)$ vibration mode at $2930 \mathrm{~cm}^{-1}$ and $\nu(\mathrm{C}=\mathrm{C})+\delta\left(\mathrm{CH}_{3}\right)$ at $306 \mathrm{~cm}^{-1}$ (if adsorbed on $\mathrm{Fe}^{\mathrm{III}}$ ) or $3048 \mathrm{~cm}^{-1}$ (if the olefin interacts with $\mathrm{Fe}^{\mathrm{II}}$ sites). These differences distinguished the adsorption of both molecules on the surface, made possible following up the separation process and even permitted quantitative analysis to be carried out.

\section{Concluding remarks}

IR spectroscopy can provide valuable and useful information on the physical-chemical properties of zeolites and MOFs, both directly and via the adsorption of adequate probe molecules. The acidity, basicity and redox sites can be identified and quantified in strength and concentration. This information is crucial for developing more efficient materials in their applications. From the point of view of catalysis, operando spectroscopic techniques can visualize, which sites play a role in the catalytic reaction behaving as active sites or hosting reacting agents or products. Vibrational spectroscopy has a special relevance in the development of structure-activity relationships for heterogeneous catalysis since it provides detailed molecular insights on the adsorbed species over the catalyst surface, including reaction intermediates, spectator species and deactivating products. In this sense, it is always useful to ask "what can we see by IR spectroscopy in this reaction process?" As shown in this chapter, IR spectroscopy is of great interest in characterizing acid-basic and redox active centres in zeolites and MOFs as it can often provide valuable information to better understand and improve the operation of these materials.

\section{References}

[1] http://www.iza-structure.org/databases/

[2] Niemantsverdriet, J.W. In Spectroscopy in Catalysis, Wiley-VCH: 2007, pp 217-249. 
[3] Auerbach, S.M., Carrado, K.A., Dutta, P.K. Handbook of zeolites Science and Technology. 2003.

[4] Karge, H.G. Micropor. Mesopor. Mater. 1998, 22, 547.

[5] Esemann, H., Forster, H., Geidel, E., Krause, K. Micropor. Mater. 1996, 6, 321.

[6] Hadjiivanov, K., Friederike, C.J. Chapter Two - Identification and Characterization of Surface Hydroxyl Groups by Infrared Spectroscopy. in Adv. Catal., Academic Press: 2014, Vol. 57, pp 99-318.

[7] Khabtou, S., Chevreau, T., Lavalley, J.C. Micropor. Mater. 1994, 3, 133.

[8] Cairon, O., Thomas, K., Chevreau, T. Micropor. Mesopor. Mater. 2001, 46, 327.

[9] Vimont, A., Goupil, J.M., Lavalley, J.C., Daturi, M., Surble, S., Serre, C., Millange, F., Ferey, G., Audebrand, N. J. Am. Chem. Soc. 2006, 128, 3218.

[10] Vimont, A., Leclerc, H., Mauge, F., Daturi, M., Lavalley, J.C., Surble, S., Serre, C., Ferey, G. J. Phys. Chem. C 2007, 111, 383 .

[11] Busca, G. Catal. Today 1998, 41, 191.

[12] Busca, G. Phys. Chem. Chem. Phys. 1999, 1, 723.

[13] Hadjiivanov, K.I., Vayssilov, G.N. Characterization of oxide surfaces and zeolites by carbon monoxide as an IR probe molecule. in Adv. Catal., 2002, Vol. 47, pp 307-511.

[14] Krahl, T., Vimont, A., Eltanany, G., Daturi, M., Kemnitz, E. J. Phys. Chem. C 2007, 111, 18317.

[15] Vimont, A., Daturi, M., Winfield, J.M. Investigation of Surface Acidity using a Range of Probe Molecules. in Functionalized Inorganic Fluorides: Synthesis, Characterization \& Properties of Nanostructured Solids, Tressssaud, A. (Ed.), John Wiley \& Sons, 2010, 101-139.

[16] Blyholder, G.J. Phys. Chem. 1964, 68, 2772.

[17] Lercher, J.A., Grundling, C., EderMirth, G. Catal. Today 1996, 27, 353.

[18] Morterra, C., Magnacca, G. Catal. Today 1996, 27, 497.

[19] Travert, A., Vimont, A., Sahibed-Dine, A., Daturi, M., Lavalley, J.C. Appl. Catal., A 20o6, 307,98 .

[20] Knözinger, H., Stolz, H. Berichte Der Bunsen-Gesellschaft Fur Physikalische Chemie 1971, 75,1055 .

[21] Lahousse, C., Aboulayt, A., Mauge, F., Bachelier, J., Lavalley, J.C. J. Mol. Catal. 1993, 84, 283.

[22] Petit, C., Mauge, F., Lavalley, J.C. Stud. Surf. Sci. Catal. 1997, 106, 157.

[23] Jacobs, P.A., Heylen, C.F.J. Catal. 1974, 34, 267.

[24] Corma, A., Rodellas, C., Fornes, V.J. Catal. 1984, 88, 374.

[25] Tsyganenko, A.A., Pozdnyakov, D.V., Filimonov, V.N. J. Mol. Struct. 1975, 29, 299.

[26] Ramis, G., Yi, L., Busca, G., Turco, M., Kotur, E., Willey, R.J.J. Catal. 1995, 157, 523.

[27] Ramis, G., Busca, G., Cristiani, C., Lietti, L., Forzatti, P., Bregani, F. Langmuir 1992, 8, 1744.

[28] Thibault-Starzyk, F., Travert, A., Saussey, J., Lavalley, J.C. Top. Catal. 1998, 6, 111.

[29] Marie, O., Thibault-Starzyk, F., Lavalley, J.C. Phys. Chem. Chem. Phys. 2000, 2, 5341.

[30] Montanari, T., Bevilacqua, M., Resini, C., Busca, G.J. Phys. Chem. B 2004, 108, 2120.

[31] Romero-Sarria, F., Marie, O., Saussey, J., Daturi, M.J. Phys. Chem. B 2005, 109, 1660.

[32] Romero-Sarria, F., Blasin-Aubé, V., Saussey, J., Marie, O., Daturi, M.J. Phys. Chem. B 20o6, 110, 13130.

[33] Montanari, T., Marie, O., Daturi, M., Busca, G. Catal. Today 2005, 110, 339.

[34] Thibault-Starzyk, F., Stan, I., Abelló, S., Bonilla, A., Thomas, K., Fernandez, C., Gilson, J.P., Pérez-Ramírez, J.J. Catal. 2009, 264, 11.

[35] Vimont, A., Thibault-Starzyk, F., Daturi, M. Chem. Soc. Rev. 2010, 39, 4928.

[36] Daturi, M., Binet, C., Lavalley, J.C., Galtayries, A., Sporken, R. Phys. Chem. Chem. Phys. 1999, 1, 5717-5724.

[37] Lavalley, J.C. Catal. Today 1996, 27, 377.

[38] Barthomeuf, D. Catal. Rev. Sci. Eng. 1996, 38, $5^{21 .}$ 
[39] Marie, O., Malicki, N., Pommier, C., Massiani, P., Vos, A., Schoonheydt, R., Geerlings, P., Henriques, C., Thibault-Starzyk, F. Chem. Commun. 2005, 1049.

[40] Payen, E., Grimblot, J., Lavalley, J.C., Daturi, M., Maugé, F. Application of Vibrational Spectroscopy in the Characterization of Oxides and Sulfides Catalysts. In Handbook of Vibrational Spectroscopy, Chalmers, J.M., Griffith, P.R., eds. Wiley: 2001, Vol. 4, pp 3005-3041.

[41] Mordenti, D., Grotz, P., Knözinger, H. Catal. Today 2001, 70, 83.

[42] Michalska, A., Daturi, M., Saussey, J., Nowak, I., Ziolek, M.T Micropor. Mesopor. Mater. 2006, 90,362 .

[43] Moulin, B., Salles, F., Bourrelly, S., Llewellyn, P.L., Devic, T., Horcajada, P., Serre, C., Clet, G., Lavalley, J.C., Daturi, M., Maurin, G., Vimont, A. Micropor. Mesopor. Mater. 2014, 195, 197.

[44] Valange, S., Beauchaud, A., Barrault, J., Gabelica, Z., Daturi, M., Can, F. J. Catal. 2007, 251,113 .

[45] Moulin, B., Oliviero, L., Bazin, P., Daturi, M., Costentin, G., Mauge, Phys. Chem. Chem. Phys. 2011, 13, 10797.

[46] Hamon, L., Leclerc, H., Ghoufi, A., Oliviero, L., Travert, A., Lavalley, J.C., Devic, T., Serre, C., Ferey, G., De Weireld, G., Vimont, A., Maurin, G.J. Phys. Chem. C 2011, 115, 2047.

[47] Mauge, F., Sahibed-Dine, A., Gaillard, M., Ziolek, M.J. Catal. 2002, 207, 353.

[48] Daturi, M., Finocchio, E., Binet, C., Lavalley, J.C., Fally, F., Perrichon, V.J. Phys. Chem. B 1999, 103,4884 .

[49] Fally, F., Perrichon, V., Vidal, H., Kaspar, J., Blanco, G., Pintado, J.M., Bernal, S., Colon, G., Daturi, M., Lavalley, J.C. Catal. Today 2000, 59, 373.

[50] Daturi, M., Finocchio, E., Binet, C., Lavalley, J.C. Fally, F., Perrichon, V., Vidal, H., Hickey, N., Kaspar, J.J. Phys.Chem. B 2000, 104, 9186.

[51] Finocchio, E., Busca, G. Catal. Today 2001, 70, 213.

[52] Binet, C., Daturi, M. Catal. Today 2001, 70, 155.

[53] Nouar, F., Breeze, M.I., Campo, B.C., Vimont, A., Clet, G., Daturi, M., Devic, T., Walton, R.I., Serre, C. Chem. Commun. 2015, 51, 14458.

[54] Ivanova, E., Mihaylov, M., Thibault-Starzyk, F., Daturi, M., Hadjiivanov, K.J. Catal. 2005, 236, 168.

[55] Lepage, M., Visser, T., Soulimani, F., Iglesias-Juez, A., Weckhuysen, B.M. J. Phys. Chem. C 2010, 114, 2282.

[56] Strauss, S.H. Dalton Trans. 200o, 1-6.

[57] Zecchina, A., Bordiga, S., Palomino, G.T., Scarano, D., Lamberti, C., Salvalaggio, M. J. Phys. Chem. B 1999, 103, 3833 .

[58] Xamena, F., Fisicaro, P., Berlier, G., Zecchina, A., Palomino, G.T., Prestipino, C., Bordiga, S., Giamello, E., Lamberti, C. J. Phys. Chem. B 2003, 107, 7036.

[59] Joyner, R., Stockenhuber, M.J. Phys. Chem. B 1999, 103, 5963.

[6o] Chen, H.Y., El-Malki, E.M., Wang, X., van Santen, R.A., Sachtler, W.M.H. J. Mol. Catal. A Chem. 2000, 162, 159 .

[61] Blasin-Aube, V., Marie, O., Saussey, J., Plesniar, A., Daturi, M., Nguyen, N., Hamon, C., Mihaylov, M., Ivanova, E., Hadjiivanov, K.J. Phys. Chem. C 2009, 113, 8387.

[62] Novakova, J., Kubelkova, L., Wichterlova, B., Juska, T., Dolejsek, Z. Zeolites 1982, 2, 17.

[63] Ivanova, E., Mihaylov, M., Hadjiivanov, K., Blasin-Aubé, V., Marie, O., Plesniar, A., Daturi, M. Appl. Catal., B 2010, 93, 325.

[64] Yoon, J.W., Seo, Y.K., Hwang, Y.K., Chang, J.S., Leclerc, H., Wuttke, S., Bazin, P., Vimont, A., Daturi, M., Bloch, E., Llewellyn, P.L., Serre, C., Horcajada, P., Greneche, J.M., Rodrigues, A.E., Ferey, G. Angew. Chem. Int. Ed. 2010, 49, 5949.

[65] Wuttke, S., Bazin, P., Vimont, A., Serre, C., Seo, Y.K., Hwang, Y.K., Chang, J.S., Ferey, G., Daturi, M. Chem. Eur.J. 2012, 18, 11959. 
[66] Yoon, J.W., Lee, J.S., Lee, S., Cho, K.H., Hwang, Y.K., Daturi, M., Jun, C.H., Krishna, R., Chang, J.S. Chem. Eur. J. 2015, 21, 18431.

[67] Thibault-Starzyk, F., Maugé, F. Infrared Spectroscopy. in Characterization of Solid Materials and Heterogeneous Catalysts, Wiley-VCH Verlag GmbH \& Co. KGaA: 2012, pp 1-48.

[68] Bazin, P., Alenda, A., Thibault-Starzyk, F. Dalton Trans. 2010, 39, 8432.

[69] Knözinger, H., Huber, S. J. Chem. Soc. Faraday Trans. 1998, 94, 2047.

[70] Zecchina, A., Spoto, G., Bordiga, S. Phys. Chem. Chem. Phys. 2005, 7, 1627.

[71] Delgado, M.R., Bulánek, R., Chlubná, P., Arean, C.O. Catal. Today 2014, 227, 45.

[72] Arean, C.O., Delgado, M.R., Nachtigall, P., Thang, H.V., Rubes, M., Bulanek, R., Chlubna-Eliasova, P. Phys. Chem. Chem. Phys. 2014, 16, 10129.

[73] Bordiga, S., Lamberti, C., Bonino, F., Travert, A., Thibault-Starzyk, F. Chem. Soc. Rev. 2015, 44, 7262.

[74] Zecchina, A., Spoto, G., Ricchiardi, G., Bordiga, S., Bonino, F., Prestipino, C., Lamberti, C. Stud. Surf. Sci. Catal. 2002, 142, 3

[75] Zecchina, A., Spoto, G., Bordiga, S. Vibrational Spectroscopy of Zeolites. in Handbook of Vibrational Spectroscopy, John Wiley \& Sons, Ltd: 2006, 3042-3071.

[76] Evans, J.C., Wright, N. Spectrochim. Acta Part A 1960, 16, 352-357.

[77] Pazé, C., Bordiga, S., Lamberti, C., Salvalaggio, M., Zecchina, A., Bellussi, G.J. Phys. Chem. B 1997, 101, 4740 .

[78] Buzzoni, R., Bordiga, S., Ricchiardi, G., Lamberti, C., Zecchina, A., Bellussi, G. Langmuir 1996, 12, 930 .

[79] Catana, G., Baetens, D., Mommaerts, T., Schoonheydt, R.A., Weckhuysen, B.M. J. Phys. Chem. B 2001, 105, 4904.

[8o] Sandoval-Díaz, L.E., González-Amaya, J.A., Trujillo, C.A. Micropor. Mesopor. Mater. 2015, 215, 229.

[81] Ward, J.W.J. Catal. 1968, 10, 34.

[82] Bulánek, R., Koudelková, E. Catal. Today 2015, 243, 62.

[83] Baran, R., Millot, Y., Onfroy, T., Krafft, J.M., Dzwigaj, S. Micropor. Mesopor. Mater. 2012, 163, 122.

[84] Janiszewska, E., Macario, A., Wilk, J., Aloise, A., Kowalak, S., Nagy, J.B., Giordano, G. Micropor. Mesopor. Mater. 2013, 182, 220.

[85] Serrano, D.P., García, R.A., Vicente, G., Linares, M., Procházková, D., Čejka, J. J. Catal. 2011, 279, 366 .

[86] Damin, A., Ricchiardi, G., Bordiga, S., Zecchina, A., Ricci, F., Spanò, G., Lamberti, C. Stud. Surf. Sci. Catal. 2001, 140, 195.

[87] Dapsens, P.Y., Mondelli, C., Pérez-Ramírez, J. Chem. Soc. Rev. 2015, 44, 7025.

[88] Sushkevich, V.L., Vimont, A., Travert, A., Ivanova, I.I.J. Phys. Chem. C 2015, 119, 17633.

[89] Dapsens, P.Y., Kusema, B.T., Mondelli, C., Pérez-Ramírez, J. J. Mol. Catal. A Chem. 2014, 388-389, 141-147.

[9o] Dapsens, P.Y., Mondelli, C., Pérez-Ramírez, J. ChemSusChem 2013, 6, 831.

[91] Kulkarni, B.S., Krishnamurty, S., Pal, S. J. Mol. Catal. A Chem. 2010, 329, 36.

[92] Otero-Areán, C., Turnes Palomino, G., Zecchina, A., Spoto, G., Bordiga, S., Roy, P. Phys. Chem. Chem. Phys. 1999, 1, 4139 .

[93] Rep, M., Palomares, A.E., Eder-Mirth, G., Van Ommen, J.G., Rösch, N., Lercher, J.A. J. Phys. Chem. B 2000, 104, 8624.

[94] Docquir, F., Toufar, H., Su, B.L. Langmuir 2001, 17, 6282.

[95] Gil, B., Zones, S.I., Hwang, S.J., Bejblová, M., Čejka, J.J. Phys. Chem. C 2008, 112, 2997.

[96] Daniell, W., Topsøe, N.Y., Knözinger, H. Langmuir 2001, 17, 6233.

[97] Hush, N.S., Williams, M.L.J. Mol. Spectrosc. 1974, 50, 349. 
[98] Phung, T.K., Busca, G. Appl. Catal., A 2015, 504, 151.

[99] Marques, J.P., Gener, I., Ayrault, P., Bordado, J.C., Lopes, J.M., Ribeiro, F.R., Guisnet, M. Compt. Rend. Chem. 2005, 8, 399.

[100] Wichterlová, B., Bortnovsky, O., Sobalík, Z., Bastl, Z.J. Catal. 2002, 210, 171.

[101] Trombetta, M., Busca, G., Storaro, L., Lenarda, M., Casagrande, M., Zambon, A. Phys. Chem. Chem. Phys. 2000, 2, 3529 .

[102] Jiang, M., Karge, H.G.J. Chem. Soc. Faraday Trans. 1996, 92, 2641.

[103] Matias, P., Sá Couto, C., Graa, I., Lopes, J.M., Carvalho, A.P., Ramôa Ribeiro, F., Guisnet, M. Appl. Catal., A 2011, 399, 100.

[104] Ordóñez, S., Díaz, E. Basic zeolites: Structure, preparation and environmental applications. in Handbook of Zeolites: Structure, Properties and Applications, 2009, pp 51-66.

[105] Wu, P., Komatsu, T., Yashima, T. J. Chem. Soc. Faraday Trans. 1996, 92, 861.

[106] van Bokhoven, J.A., Lamberti, C. Coordin. Chem. Rev. 2014, 277-278, 275.

[107] Chakarova, K., Andonova, S., Dimitrov, L., Hadjiivanov, K. Micropor. Mesopor. Mater. 2016, $220,188$.

[108] Vimont, A., Thibault-Starzyk, F., Lavalley, J.C.J. Phys. Chem. B 2000, 104, 286.

[109] Ricchiardi, G., Damin, A., Bordiga, S., Lamberti, C., Spanò, G., Rivetti, F., Zecchina, A. J. Am. Chem. Soc. 2001, 123, 11409.

[110] Sánchez-Sánchez, M., Blasco, T. Catal. Today 2009, 143, 293.

[111] Hattori, H. Chem. Rev. 1995, 95, 537.

[112] Siporin, S.E., McClaine, B.C., Davis, R.J. Langmuir 2003, 19, 4707.

[113] Belin, T., Mve Mfoumou, C., Mignard, S., Pouilloux, Y. Micropor. Mesopor. Mater. 2013, 182, 109.

[114] Schoonheydt, R.A., Geerlings, P., Pidko, E.A., van Santen, R.A.J. Mater. Chem. 2012, 22, 18705 .

[115] Uvarova, E.B., Kustov, L.M., Kazansky, V.B. Stud. Surf. Sci. Catal. 1995, 94, 254.

[116] Lavalley, J.C., Lamotte, J., Travert, A., Czyzniewska, J., Ziolek, M.J. Chem. Soc. Faraday Trans. 1998, 94, 331.

[117] Karge, H.G., Raskó, J.J. Colloid Interface Sci. 1978, 64, 522.

[118] Karge, H.G., Ziółek, M., Łaniecki, M. Zeolites 1987, 7, 197.

[119] Montanari, T., Marie, O., Daturi, M., Busca, G. Appl. Catal. B 2007, 71, 216.

[120] Howarth, A.J., Peters, A.W., Vermeulen, N.A., Wang, T.C., Hupp, J.T., Farha, O.K. Chem. Mater. 2017, 29, 26.

[121] Zhou, H.J., Kitagawa, S. Chem. Soc. Rev. 2014, 43, 5415.

[122] Furukawa, H., Cordova, K.E., O'Keeffe, M., Yaghi, O.M. Science 2013, 341.

[123] Fitzgerald, S.A., Schloss, J.M., Pierce, C.J., Thompson, B., Rowsell, J.L.C., Yu, K., Schmidt, J.R. J. Phys. Chem. C 2015, 119, 5293.

[124] Chen, Y., Wang, H., Li, J., Lockard, J.V.J. Mater. Chem. A 2015, 3, 4945.

[125] Vitillo, J.G., Regli, L., Chavan, S., Ricchiardi, G., Spoto, G., Dietzel, P.D.C., Bordiga, S., Zecchina, A. J. Am. Chem. Soc. 2008, 130, 8386.

[126] Tan, K., Zuluaga, S., Gong, Q., Gao, Y., Nijem, N., Li, J., Thonhauser, T., Chabal, Y.J. Chem. Mater. 2015, 27, 2203.

[127] Valenzano, L., Civalleri, B., Chavan, S., Palomino, G.T., Areán, C.O., Bordiga, S. J. Phys. Chem. $C_{2010,114,11185 \text {. }}$

[128] Bhattacharjee, S., Lee, Y.-R., Puthiaraj, P., Cho, S.-M., Ahn, W.-S. Catal. Surv. Asia 2015, 19, 203.

[129] Dhakshinamoorthy, A., Alvaro, M., Garcia, H. Chem. Commun. 2012, 48, 11275.

[130] Szeto, K.C., Lillerud, K.P., Tilset, M., Bjørgen, M., Prestipino, C., Zecchina, A., Lamberti, C., Bordiga, S.J. Phys. Chem. B 2006, 110, 21509.

[131] Huang, Y.-B., Liang, J., Wang, X.-S., Cao, R. Chem. Soc. Rev. 2017, 46, 126.

[132] Xue, Z., Jiang, J., Ma, M.-G., Li, M.-F., Mu, T. ACS Sustain. Chem. Eng. 2017, 5, 2623. 
[133] Liang, Q., Zhang, M., Zhang, Z., Liu, C., Xu, S., Li, Z.J. Alloys Compd. 2017, 690, 123.

[134] Cavka, J.H., Jakobsen, S., Olsbye, U., Guillou, N., Lamberti, C., Bordiga, S., Lillerud, K.P. J. Am. Chem. Soc. 2008, 130, 13850 .

[135] Shearer, G.C., Forselv, S., Chavan, S., Bordiga, S., Mathisen, K., Bjørgen, M., Svelle, S., Lillerud, K.P. Top. Catal. 2013, 56, 770.

[136] Morterra, C., Bolis, V., Magnacca, G.J. Chem. Soc. Faraday Trans. 1996, 92, 1991.

[137] Chakarova, K., Hadjiivanov, K. Micropor. Mesopor. Mater. 2013, 177, 59.

[138] Cairon, O., Chevreau, T., Lavalley, J.C.J. Chem. Soc. Faraday Trans. 1998, 94, 3039.

[139] Geobaldo, F., Lamberti, C., Ricchiardi, G., Bordiga, S., Zecchina, A., Palomino, G.T., Arean, C.O.J. Phys. Chem. 1995, 99, 11167.

[140] Zhang, Y., Lucier, B.E.G., Terskikh, V.V., Zheng, R., Huang, Y. Solid State Nucl. Magn. Reson. $2017,84,118$.

[141] Wack, J., Siegel, R., Ahnfeldt, T., Stock, N., Mafra, L., Senker, J.J. Phys. Chem. C 2013, 117, 19991.

[142] Loiseau, T., Serre, C., Huguenard, C., Fink, G., Taulelle, F., Henry, M., Bataille, T., Férey, G. Chem. Eur. J. 2004, 10, 1373.

[143] Mihaylov, M., Andonova, S., Chakarova, K., Vimont, A., Ivanova, E., Drenchev, N., Hadjiivanov, K. Phys. Chem. Chem. Phys. 2015, 17, 24304.

[144] Ravon, U., Chaplais, G., Chizallet, C., Seyyedi, B., Bonino, F., Bordiga, S., Bats, N., Farrusseng, D. ChemCatChem 2010, 2, 1235 .

[145] Nouar, F., Devic, T., Chevreau, H., Guillou, N., Gibson, E., Clet, G., Daturi, M., Vimont, A., Greneche, J.M., Breeze, M.I., Walton, R.I., Llewellyn, P.L., Serre, C. Chem. Commun. 2012, 48, 10237 . 
